\title{
Photochemical Processes in a Rhenium(I) Tricarbonyl N-Heterocyclic Carbene Complex Studied by Time-Resolved Measurements
}

Tatsuhiko Mukuta ${ }^{1}$, Peter V. Simpson², Jamila G. Vaughan ${ }^{2}$, Brian W. Skelton ${ }^{3}$, Stefano Stagni ${ }^{4}$, Massimiliano Massi ${ }^{2}$, Kazuhide Koike ${ }^{5}$, Osamu Ishitani ${ }^{1}$, Ken Onda $^{6,7, *}$

${ }^{1}$ Department of Chemistry, School of Science, Tokyo Institute of Technology, O-okayama, Meguro-ku, Tokyo 152-8551, Japan

${ }^{2}$ Department of Chemistry and Nanochemistry Research Institute-Curtin University, Kent Street, Bentley 6102 WA, Australia

${ }^{3}$ Centre for Microscopy, Characterisation and Analysis, University of Western Australia, Crawley 6009 WA, Australia.

${ }^{4}$ Department of Industrial Chemistry "Toso Montanari," University of Bologna, viale del Risorgimento 4, I-40136 Bologna, Italy.

${ }^{5}$ National Institute of Advanced Industrial Science and Technology, 16-1 Onogawa, Tsukuba 305-8569, Japan

${ }^{6}$ Interactive Research Center of Science, Tokyo Institute of Technology, Nagatsuta, Midori-ku, Yokohama, Kanagawa 226-8502, Japan

${ }^{7}$ PRESTO, Japan Science and Technology Agency (JST), 4-1-8 Honcho, Kawaguchi, Saitama 332-0012, Japan

*Corresponding Author

Interactive Research Center of Science, Tokyo Institute of Technology,

S1-8, 4259 Nagatsuta, Midori-ku, Yokohama 226-8502, Japan

Phone/fax: +81- 45-924-5891

Email: onda.k.aa@m.titech.ac.jp

\begin{abstract}
We carried out time-resolved infrared (TR-IR) and emission lifetime measurements on a $\operatorname{Re}(\mathrm{I})$ carbonyl complex having an N-heterocyclic carbene ligand, namely, fac- $\left[\operatorname{Re}(\mathrm{CO})_{3}(\mathrm{PyImPh}) \mathrm{Br}\right]$, under photochemically reactive (in solution in acetonitrile) and non-reactive (in solution in dichloromethane) conditions to investigate the mechanism of
\end{abstract}


photochemical ligand substitution reactions. The TR-IR measurements revealed that no reaction occurs on a picosecond timescale and the cationic product, namely, fac- $\left[\operatorname{Re}(\mathrm{CO})_{3}(\mathrm{PyImPh})(\mathrm{MeCN})\right]^{+}$, is produced on a nanosecond timescale only in solution in acetonitrile, which indicates that the reaction proceeds thermally from the excited state. Because no other products were observed by TR-IR, we concluded that this cationic product is an intermediate species for further reactions. The measurements of the temperature-dependent emission lifetime and analysis using transition state theory revealed that the photochemical substitution reaction proceeds from a metal-to-ligand charge transfer excited state, the structure of which allows the potential coordination of a solvent molecule. Thus, the coordinating capacity of the solvent determines whether the reaction proceeds or not. This mechanism is different from those of photochemical reactions of other types of $\operatorname{Re}(\mathrm{I})$ carbonyl complexes owing to the unique characteristics of the carbene ligand. 


\section{Introduction}

Rhenium(I) tricarbonyl complexes of the formula $f a c-\left[\operatorname{Re}(\operatorname{diim})(\mathrm{CO})_{3} \mathrm{~L}\right]^{\mathrm{n}+}(\operatorname{diim}=$ diimine ligand, $\mathrm{L}=$ monodentate ligand, $\mathrm{n}=0$ or 1 ) undergo $\mathrm{CO}$ dissociation reactions upon photoexcitation under certain conditions, followed by substitution reactions with other ligands such as coordinating solvent molecules. In some cases, isomerization might also occur prior to coordination of the solvent molecule ${ }^{1-7}$. Because the selectivity of photochemical reactions differs from that of thermal reactions, photochemical substitution of $\mathrm{CO}$ ligands is utilized for the synthesis of various photofunctional materials ${ }^{8-10}$. Moreover, it is well known that fac- $\left[\operatorname{Re}(\operatorname{diim})(\mathrm{CO})_{3} \mathrm{~L}\right]^{\mathrm{n}+}$ complexes are promising components for $\mathrm{CO}_{2}$ photoreduction systems ${ }^{11}$. Thus, the mechanisms of these photoreactions have been intensively investigated and are categorized into the following two main groups. Type I reactions proceed via a metal-centered state $\left({ }^{3} \mathrm{MC}\right)$, which is thermally populated from a metastable triplet metal-to-ligand charge transfer state $\left({ }^{3} \mathrm{MLCT}\right)^{2}$. A typical example is dissociative substitution of $\mathrm{CO}$ in $f a c-\left[\operatorname{Re}(\mathrm{CO})_{3}(\mathrm{bpy})\left(\mathrm{PR}_{3}\right)\right]^{+}$. In type II reactions, the substitution proceeds directly from higher excited states populated after ultraviolet (UV) irradiation $(<313 \mathrm{~nm})^{3-7}$, of which a typical example is provided by $f a c-\left[\operatorname{Re}(\mathrm{CO})_{3}(\mathrm{bpy}) \mathrm{Cl}\right]^{3-5}$.

Recently, a new series of $\operatorname{Re}(\mathrm{I})$ tricarbonyl complexes coordinated to $\mathrm{N}$-heterocyclic carbene (NHC) ligands have been synthesized $^{12-16}$, and it has been shown that some of these complexes undergo photochemical

substitution of one $\mathrm{CO}$ ligand $^{14-16}$. Furthermore, it has also been found that some of these complexes act as $\mathrm{CO}_{2}$ reduction catalysts $^{17-19}$. However, the

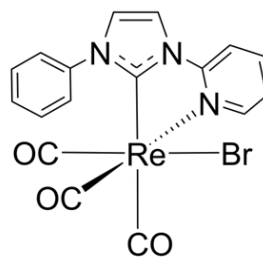

$\left[\operatorname{Re}(\mathrm{CO})_{3}(\mathrm{Py} \mid \mathrm{mPh}) \mathrm{Br}\right]$

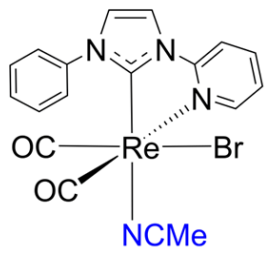

Product 1

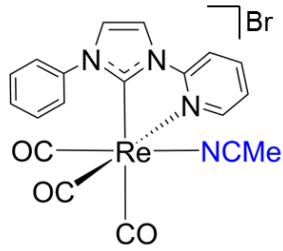

Product 2

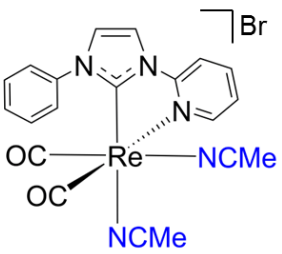

Product 3

Figure 1: Structures of $\left[\operatorname{Re}(\mathrm{CO})_{3}(\mathrm{PyImPh}) \mathrm{Br}\right]$ and its photoreaction products upon irradiation by UV light of a solution in $\mathrm{MeCN}$ of $\left[\operatorname{Re}(\mathrm{CO})_{3}(\mathrm{PyImPh}) \mathrm{Br}\right]$.

fundamental photochemical processes in the reactions of these complexes differ from both type I and type II mechanisms for $\operatorname{Re}(\mathrm{I})$ diimine carbonyl complexes and have yet to be elucidated. Figure 1 shows the products of the photoreaction of $f a c-\left[\operatorname{Re}(\mathrm{CO})_{3}(\mathrm{PyImPh}) \mathrm{Br}\right](\mathrm{PyImPh}=$ 1-phenyl-3-(2-pyridyl)imidazol-2-ylidene). When a solution in acetonitrile (MeCN) of $f a c-\left[\operatorname{Re}(\mathrm{CO})_{3}(\mathrm{PyImPh}) \mathrm{Br}\right]$ is irradiated by $\mathrm{UV}$ light $(370 \mathrm{~nm})$, which corresponds to excitation 
into the metal-to-ligand charge transfer/ligand-to-ligand charge transfer (MLCT/LLCT) manifold, the three products shown in Figure 1 are detected. Product 1 is a neutral dicarbonyl complex in which the CO ligand located trans to the NHC ligand is substituted by a molecule of $\mathrm{MeCN}$. Product 2 is a cationic tricarbonyl complex in which the $\mathrm{Br}^{-}$ligand is substituted by a molecule of MeCN. Product 3 is a cationic dicarbonyl complex in which both the $\mathrm{Br}^{-}$ligand and the CO ligand located trans to the NHC ligand are substituted by a molecule of MeCN. This photoreaction has the following characteristics ${ }^{14-16}$ :

(1) The reaction occurs in $\mathrm{MeCN}$ but does not occur in dichloromethane $\left(\mathrm{CH}_{2} \mathrm{Cl}_{2}\right)$ or acetone $\left(\mathrm{Me}_{2} \mathrm{CO}\right)$;

(2) The reaction occurs even at $233 \mathrm{~K}$, which is close to the freezing point of $\mathrm{MeCN}$, which indicates that the mechanism differs from type I; and

(3) The reaction occurs upon irradiation with a relatively longer wavelength $(>400 \mathrm{~nm})$, which differs from the type II mechanism.

In order to reveal the mechanism of this reaction having these unique characteristics, we investigated it by means of two time-resolved techniques: time-resolved infrared spectroscopy (TR-IR) $)^{5,20-25}$ and temperature-dependent emission lifetime measurements. TR-IR is a powerful tool that allows reaction processes to be followed step by step, because the intermediate species can be identified from their vibrational spectral pattern at each delay time. We therefore measured the temporal evolution of the TR-IR spectra of $f a c$ - $\left[\mathrm{Re}(\mathrm{CO})_{3}(\mathrm{PyImPh}) \mathrm{Br}\right]$ after photoexcitation at 355 or $400 \mathrm{~nm}$ in solution in $\mathrm{MeCN}$, in which the photoreactions occur (reactive conditions), as well as in solution in $\mathrm{CH}_{2} \mathrm{Cl}_{2}$, in which the photoreactions do not occur (non-reactive conditions). We then combined these data with emission lifetime measurements made at various temperatures, as well as calculations based on transition state theory, to illustrate the detailed mechanism of this unique photochemical ligand substitution reaction. 


\section{Experimental}

\subsection{General considerations}

All reagents and solvents were purchased from Sigma Aldrich, Strem, or Alfa Aesar and were used as received without further purification. All reactions were conducted under an atmosphere of $\mathrm{N}_{2}$. All reactions and subsequent manipulations were performed in the dark where possible. $f a c-\left[\operatorname{Re}(\mathrm{CO})_{3}(\mathrm{PyImPh}) \mathrm{Br}\right]$ was prepared as previously described ${ }^{15}$. Nuclear magnetic resonance (NMR) spectra were recorded using a Bruker Avance 400 spectrometer (400.1 MHz for ${ }^{1} \mathrm{H}$; $100 \mathrm{MHz}$ for ${ }^{13} \mathrm{C}$ ) at $300 \mathrm{~K}$. All the NMR spectra were calibrated to residual solvent signals. Infrared (IR) spectra were recorded using an attenuated total reflectance (ATR) PerkinElmer Spectrum 100 Fourier transform IR (FT-IR) spectrometer with a diamond stage. IR spectra were recorded from 4000 to $650 \mathrm{~cm}^{-1}$. The intensities of the IR bands are reported as strong (s), medium (m), or weak (w), with broad (br) bands also specified. Elemental analyses were performed at Curtin University using a Thermo Finnigan EA 1112 series flash elemental analyzer.

\subsection{Synthesis of $f a c-\left[\operatorname{Re}(\mathrm{CO})_{3}(\mathrm{PyImPh})(\mathrm{MeCN})\right]\left[\mathrm{BF}_{4}\right]$}

$\mathrm{AgBF}_{4}$ (44.5 mg, $0.228 \mathrm{mmol}$ ) was weighed into a Schlenk flask under $\mathrm{N}_{2}$. Dry MeCN $\left(8 \mathrm{~mL}\right.$ ) was added to the flask and the mixture was sparged with $\mathrm{N}_{2}$ for $30 \mathrm{~min}$. fac-[Re(CO) $\left.)_{3}(\mathrm{PyImPh}) \mathrm{Br}\right](101 \mathrm{mg}, 0.176 \mathrm{mmol})$ was added and the mixture was heated under reflux for $20 \mathrm{~h}$. The pale yellow solution was separated from excess silver salts by cannula filtration into a pencil Schlenk flask and then layered with dry and degassed diethyl ether. After three days, pale yellow crystals formed. The diethyl ether and $\mathrm{MeCN}$ were removed by syringe and the crystals were triturated with fresh diethyl ether $(3 \mathrm{~mL})$. The crystals were then dried under high vacuum for $8 \mathrm{~h}$ to afford $f a c$ - $\left[\operatorname{Re}(\mathrm{CO})_{3}(\mathrm{PyImPh})(\mathrm{MeCN})\right]\left[\mathrm{BF}_{4}\right]$. Yield: $60 \mathrm{mg}, 55 \%$. ${ }^{1} \mathrm{H} \mathrm{NMR} \delta / \mathrm{ppm}\left(\mathrm{CDCl}_{3}\right): 8.75\left(1 \mathrm{H}, \mathrm{ddd},{ }^{3} J_{\mathrm{H}, \mathrm{H}}=5.6 \mathrm{~Hz},{ }^{4} J_{\mathrm{H}, \mathrm{H}}=1.7 \mathrm{~Hz},{ }^{5} J_{\mathrm{H}, \mathrm{H}}=0.7 \mathrm{~Hz}, \mathrm{H}^{\prime}\right)$, $8.24\left(1 \mathrm{H}, \mathrm{ddd},{ }^{3} J_{\mathrm{H}, \mathrm{H}}=8.4 \mathrm{~Hz},{ }^{3} J_{\mathrm{H}, \mathrm{H}}=7.6 \mathrm{~Hz},{ }^{4} J_{\mathrm{H}, \mathrm{H}}=1.7 \mathrm{~Hz}, \mathrm{H} 4^{\prime}\right), 8.12\left(1 \mathrm{H}, \mathrm{d},{ }^{3} J_{\mathrm{H}, \mathrm{H}}=2.2 \mathrm{~Hz}\right.$, $\mathrm{H} 4), 8.09\left(1 \mathrm{H}, \mathrm{ddd},{ }^{3} J_{\mathrm{H}, \mathrm{H}}=8.4 \mathrm{~Hz},{ }^{4} J_{\mathrm{H}, \mathrm{H}}=1.2 \mathrm{~Hz},{ }^{5} J_{\mathrm{H}, \mathrm{H}}=0.7 \mathrm{~Hz}, \mathrm{H} 3^{\prime}\right), 7.54-7.63(5 \mathrm{H}, 3 \times \mathrm{m}, 3$ $\times \mathrm{ArCH}), 7.42\left(1 \mathrm{H}, \mathrm{ddd},{ }^{3} J_{\mathrm{H}, \mathrm{H}}=7.6 \mathrm{~Hz},{ }^{3} J_{\mathrm{H}, \mathrm{H}}=5.6 \mathrm{~Hz},{ }^{4} J_{\mathrm{H}, \mathrm{H}}=1.2 \mathrm{~Hz}, \mathrm{H} 5^{\prime}\right), 7.37\left(1 \mathrm{H}, \mathrm{d},{ }^{3} J_{\mathrm{H}, \mathrm{H}}=\right.$ $2.2 \mathrm{~Hz}, \mathrm{H} 5), 2.26$ (3H, s, $\left.\mathrm{CH}_{3}\right) .{ }^{13} \mathrm{C} \mathrm{NMR} \delta / \mathrm{ppm}\left(\mathrm{CDCl}_{3}\right): 194.7$ (CO), 192.2 (CO), 189.6 (C2), 186.9 (CO), 154.2 (C2'), 153.0 (C6'), 142.9 (C4'), 139.1 (Ar C), 130.3 ( $\mathrm{Ar} \mathrm{CH}), 130.2(\mathrm{Ar} \mathrm{CH})$, 126.4 (Ar CH), $125.1(\mathrm{C} 5), 124.3\left(\mathrm{C5}^{\prime}\right), 123.3\left(\mathrm{NCCH}_{3}\right), 118.9(\mathrm{C} 4), 114.6\left(\mathrm{C}^{\prime}\right), 3.66\left(\mathrm{NCCH}_{3}\right)$.

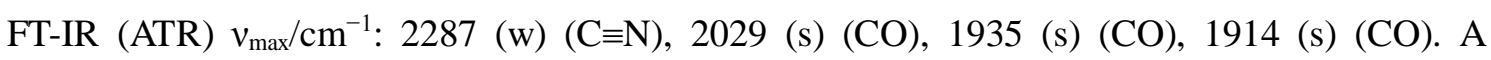
satisfactory elemental analysis could not be achieved owing to the instability of the complex toward air, light, and moisture. Crystals of $f a c-\left[\operatorname{Re}(\mathrm{CO})_{3}(\mathrm{PyImPh})(\mathrm{MeCN})\right]\left[\mathrm{BPh}_{4}\right]$, which were made by anion metathesis from $f a c-\left[\operatorname{Re}(\mathrm{CO})_{3}(\mathrm{PyImPh})(\mathrm{MeCN})\right][\mathrm{OTf}]$ and were suitable for $\mathrm{X}$-ray diffraction studies, were grown by vapor diffusion between diethyl ether and a solution in 
methanol of the complex. The X-ray structure and selected geometric parameters that were determined are shown in Figure $\mathrm{S} 1$ and Table S1, respectively. $f a c-\left[\operatorname{Re}(\mathrm{CO})_{3}(\mathrm{PyImPh})(\mathrm{MeCN})\right][\mathrm{OTf}]$ was synthesized following previously published procedures where an a slight excess of AgOTf (1.1 eq.) was added to a solution of fac- $\left[\operatorname{Re}(\mathrm{CO})_{3}(\mathrm{PyImPh}) \mathrm{Cl}\right]$ in acetonitrile, and the mixture was refluxed in the dark, followed by filtration of the precipitated silver chloride over celite. The acetonitrile solutions of $f a c-\left[\operatorname{Re}(\mathrm{CO})_{3}(\mathrm{PyImPh})(\mathrm{MeCN})\right][\mathrm{OTf}]$ was used as received due to the reactive nature of the solvato-complex.

\subsection{TR-IR measurements}

TR-IR measurements were carried out by the pump-probe method using an experimental setup described in previous papers ${ }^{22-25}$. A Ti:sapphire regenerative amplifier (Spectra Physics Spitfire Ace) provided an output with a pulse duration of $120 \mathrm{fs}$, a central wavelength of $800 \mathrm{~nm}$, and a repetition rate of $1 \mathrm{kHz}$. The output was split into two parts. A mid-IR probe pulse (bandwidth $=150 \mathrm{~cm}^{-1}$, tunable range $=1000-3700 \mathrm{~cm}^{-1}$ ) was obtained using an optical parametric amplifier equipped with a difference frequency generation crystal (Light Conversion TOPAS Prime) from one part of the output. For measurements in the temporal range from $0.2 \mathrm{ps}$ to $1 \mathrm{~ns}$, a $400 \mathrm{~nm}$ pump pulse was generated by doubling the other part of the output. A delay time between the $400 \mathrm{~nm}$ pump pulse and the IR probe pulse was created by a mechanical delay stage. In order to remove the effect of rotational relaxation of the molecules, the angle between the polarizations of the pump and probe pulses was set to the magic angle $\left(=54.7^{\circ}\right)$. For measurements in the range over $1 \mathrm{~ns}$, a $355 \mathrm{~nm}$ pump pulse was obtained by tripling the output of a Nd:YVO laser (InnoLas picolo AOT-YVO-25, central wavelength $=1064 \mathrm{~nm}$, pulse duration $=600 \mathrm{ps}$ ), which was electronically synchronized with the Ti:sapphire amplifier. A delay time between the $355 \mathrm{~nm}$ pump pulse and the IR probe pulse was created by an electronic delay generator (Stanford Research Systems DG645). Typical fluence of the $400 \mathrm{~nm}$ pump pulse is about $20 \mathrm{~mJ} / \mathrm{cm}^{2}$, and that of the $532 \mathrm{~nm}$ pump pulse is about $\mathrm{xx} \mathrm{mJ} / \mathrm{cm}^{2}$. In our previous researches, we confirmed that the linearity of the photophysical and photochemical processes are maintained with such excitation fluence. The transmitted probe pulse was dispersed by a grating and then acquired by a 64-channel mercury-cadmium-tellurium IR detector array (Infrared Systems Development FPAS-6416-D). The concentration of the sample solutions was $1 \mathrm{mM}$ and all measurements were carried out at room temperature. In order to eliminate quenching by the oxygen in air, Ar gas was continuously bubbled into the sample solutions during the measurements. Steady-state IR spectra under photoirradiation were recorded using an FT-IR spectrometer (Shimadzu IR Prestige-21). 


\subsection{Temperature-dependent emission lifetime measurements}

Temperature-dependent emission lifetimes were measured using a time-correlated single-photon counting system (Horiba FluoroCube) equipped with a $371 \mathrm{~nm}$ pulsed LED as the excitation source (instrumental response time $<1 \mathrm{~ns}$ ). The concentration of the sample solutions was $0.05 \mathrm{mM}$. Oxygen dissolved in the sample solutions was removed by the freeze-pump-thaw method. The temperature was varied from 213 to $303 \mathrm{~K}$ when $\mathrm{CH}_{2} \mathrm{Cl}_{2}$ was the solvent and from 233 to $313 \mathrm{~K}$ when $\mathrm{MeCN}$ was the solvent.

\subsection{Quantum chemical calculations}

Quantum chemical calculations were performed with the Gaussian 09 package ${ }^{26}$. All calculations were performed using the mPW1PW91 functional, and the LanL2DZ basis set, which was extended by a polarization function, was employed for all atoms. Solvent effects were considered using the polarizable conductor calculation model. The experimental ground and excited states were regarded as the calculated lowest singlet $\left(\mathrm{S}_{0}\right)$ and lowest triplet $\left(\mathrm{T}_{1}\right)$ states, respectively, and their optimized geometries were calculated separately. The IR absorption intensities were estimated from these geometries with a scaling factor of 0.97 . The TR-IR spectra were simulated by subtraction of the absorption spectrum of the $\mathrm{S}_{0}$ state from the absorption spectrum of the $\mathrm{T}_{1}$ state. Time-dependent density functional theory (TD-DFT) calculations on the optimized structure of the $\mathrm{T}_{1}$ state were performed to investigate the excited states that exist near the lowest $\mathrm{T}_{1}$ state.

\section{Results and discussion}

\subsection{TR-IR on the picosecond timescale}

Figures 2(a) and (b) show the TR-IR spectra of $\left[\operatorname{Re}(\mathrm{CO})_{3}(\mathrm{PyImPh}) \mathrm{Br}\right]$ in the range of $1850-2100 \mathrm{~cm}^{-1}$ for periods of up to $50 \mathrm{ps}$ after photoexcitation under non-reactive $(1 \mathrm{mM}$ solution in $\left.\mathrm{CH}_{2} \mathrm{Cl}_{2}\right)$ and reactive $(1 \mathrm{mM}$ solution in $\mathrm{MeCN})$ conditions, respectively. The stretching vibrations of $\mathrm{CO}$ ligands that coordinate to the central metal are generally located in this region in transition metal complexes ${ }^{27}$. In both spectra, there are three bleaching (downward) bands and three transient absorption (upward) bands. The relative intensity and position of these bands are almost the same under both conditions. The bleaching bands at 1895 and $1925 \mathrm{~cm}^{-1}$ are assigned to asymmetric vibrations, whereas the bleaching band at $2021 \mathrm{~cm}^{-1}$ is assigned to symmetric vibrations of the three CO ligands in the ground state (GS). The broad transient absorption band at $1962 \mathrm{~cm}^{-1}$ is assigned to asymmetric vibrations, whereas the narrow band at $2045 \mathrm{~cm}^{-1}$ is assigned to symmetric vibrations in the excited state. The blue shift in the CO vibrations by about $30-70 \mathrm{~cm}^{-1}$ after photoexcitation indicates that the excited state is the typical MLCT state of transition metal tricarbonyl complexes ${ }^{5,20,21,28}$. This means that the C-O 
bonds are strengthened by a reduction in $\pi$ back donation to the $\pi^{*}$ orbitals of the CO ligands by the Re center when an electron is promoted to the $\pi^{*}$ orbitals of the NHC ligand. For both the spectra in Figures 2(a) and (b), the band intensities and shapes are almost independent of the delay time, which indicates that the vibrational modes in this region are relaxed into the lowest vibrational revel within 2 ps after photoexcitation. Furthermore, this similarity indicates that no $\mathrm{CO}$ dissociation reaction occurs up to $50 \mathrm{ps}$.

For further analysis of the character of the ${ }^{3} \mathrm{MLCT}$ state, we carried out quantum chemical calculations. Figure 2(c) shows the calculated TR-IR spectrum. The green and red bars represent the calculated IR absorption intensities for each vibrational mode in the ground $\left(\mathrm{S}_{0}\right)$ and excited $\left(\mathrm{T}_{1}\right)$ states, respectively. The intensities for the GS are shown in the negative direction because the changes in IR absorption in the GS appear as negative signals in the TR-IR spectra. The black solid line represents the convolved spectrum derived from these bars, assuming that each band is expressed by a Gaussian function with a full width at half maximum of $15 \mathrm{~cm}^{-1}$. The calculated spectrum is in agreement with the experimental spectra for both the conditions shown in Figures 2(a) and (b). Therefore, we will discuss the electronic and structural characteristics on the basis of these calculations.

Figure 3 shows the calculated frontier orbitals of the $S_{0}$ and $T_{1}$ states. The highest occupied molecular orbital (HOMO) of the $\mathrm{S}_{0}$ state is distributed over the $5 \mathrm{~d}$ orbital of the Re atom, the $\pi$ orbital of the imidazolyl ring, and the $4 \mathrm{p}$ orbital of the $\mathrm{Br}^{-}$ligand. The upper singly occupied molecular orbital (SOMO2) of the $\mathrm{T}_{1}$ state, in which the higher-energy electron is located, is distributed over the $\pi^{*}$ orbitals of the pyridine and imidazolyl rings, the $\pi^{*}$ orbitals of the $\mathrm{CO}$ ligands, and the $4 \mathrm{p}$ orbital of the $\mathrm{Br}^{-}$ligand. The difference in distribution between the $\mathrm{HOMO}$ and SOMO2 indicates that photoexcitation induces electron transfer from the Re center and $\mathrm{Br}^{-}$ligand mainly to the pyridine ring and partially to the imidazolyl ring. Figure 4 shows the optimized geometries of the $\mathrm{S}_{0}$ and $\mathrm{T}_{1}$ states. The most remarkable change in the structure is the bending of the Br-Re-CO(3) linkage highlighted by the red shaded areas. This angle is changed by $11^{\circ}$. This change in the angle is probably caused by a reduction in $\pi$ back donation to the $\mathrm{CO}$ ligands, as a similar change in angle was previously observed in ring-shaped $\operatorname{Re}(\mathrm{I})$ dicarbonyl complexes ${ }^{24}$. The major differences in the bond lengths and angles are listed in Table S2.

Figure 5 shows the phases of the three $\mathrm{CO}$ stretching vibrations as estimated from the calculated normal vibrational modes. Modes 1 and 2 are assigned to asymmetric vibrations and Mode 3 is assigned to symmetric vibrations of the three CO ligands. The shift in wavenumber of each band upon the transition from the $S_{0}$ to the $T_{1}$ state, $\Delta\left(T_{1}-S_{0}\right)$, depends on the vibrational mode and is $+64,+27$, and $+8 \mathrm{~cm}^{-1}$ for Mode 1,2 , and 3, respectively. The differences in the magnitude of these blue shifts could be explained by the distribution of the SOMO $2^{28}$. As was 
mentioned above, the SOMO2 is distributed not only over the $\pi^{*}$ orbitals of the pyridine and imidazolyl rings but also over the $\pi^{*}$ orbitals of the CO ligands. Therefore, the electron densities on the CO ligands in the same plane as the pyridine and imidazolyl rings, which are indicated by $\mathrm{CO}(1)$ and $\mathrm{CO}(2)$, are higher than that on the $\mathrm{CO}$ ligand located trans to the $\mathrm{Br}^{-}$ligand, which is indicated by $\mathrm{CO}(3)$. This difference in the electron density on the $\mathrm{CO}$ ligands and structural changes probably lead to the dependence of the blue shift on the vibrational mode. 


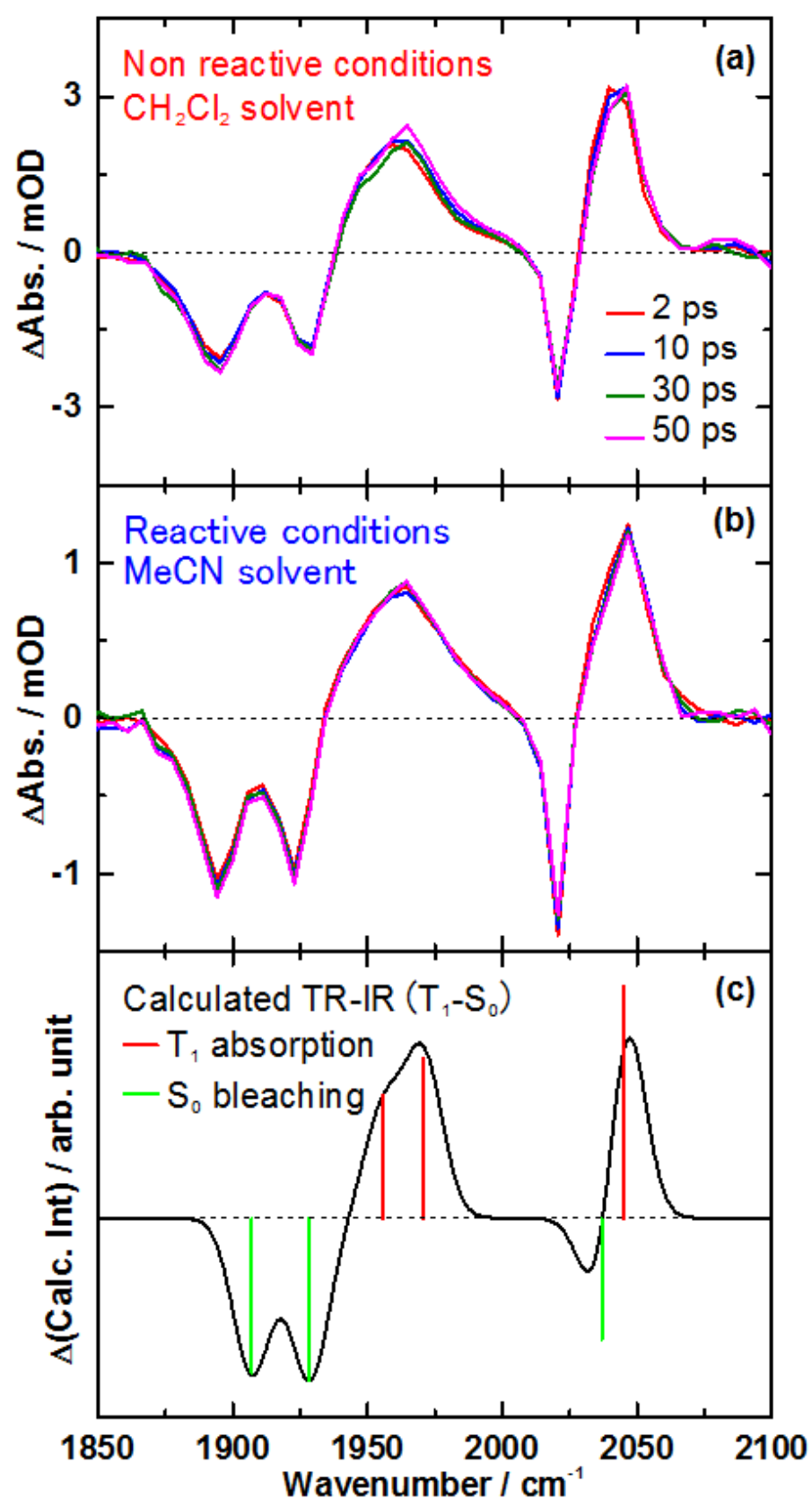

Figure 2: Temporal evolution of TR-IR spectra of $\left[\operatorname{Re}(\mathrm{CO})_{3}(\mathrm{PyImPh}) \mathrm{Br}\right]$ after excitation at 400 nm under (a) non-reactive (in solution in $\mathrm{CH}_{2} \mathrm{Cl}_{2}$ ) and (b) reactive (in solution in $\mathrm{MeCN}$ ) conditions. (c) Calculated TR-IR spectrum. The bars in the spectrum provide the wavenumber and intensity of each CO stretching mode shown in Figure 5, and their colors indicate absorption of the $\mathrm{T}_{1}$ state (red) and bleaching of the $\mathrm{S}_{0}$ state (green). 
(a) $\mathrm{S}_{0}$ state $\mathrm{HOMO}$
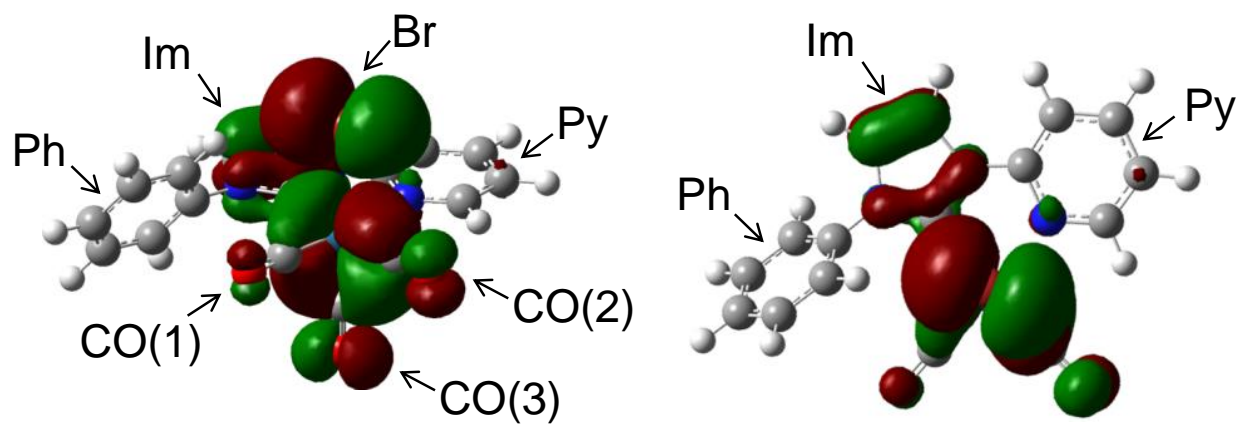

(b) $\mathrm{T}_{1}$ state $\mathrm{SOMO} 2$
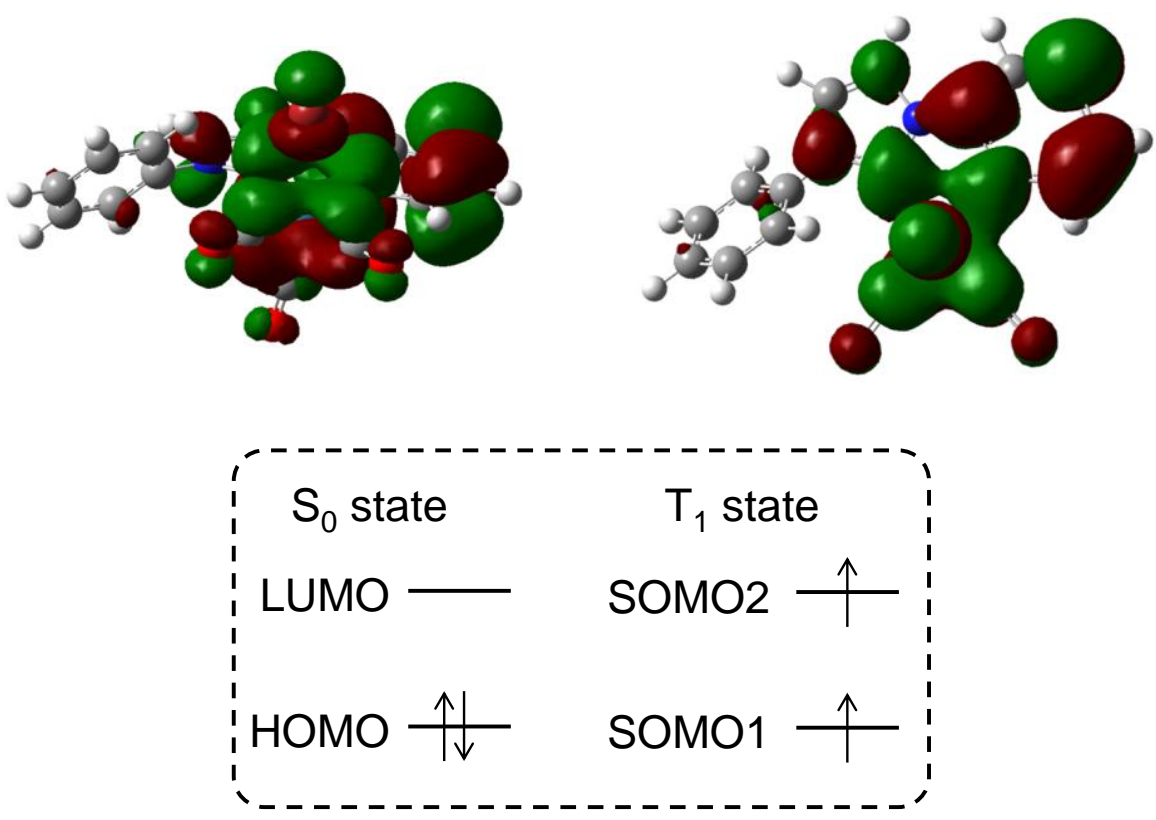

Figure 3: Calculated frontier orbitals of $\left[\mathrm{Re}(\mathrm{CO})_{3}(\mathrm{PyImPh}) \mathrm{Br}\right]$. (a) $\mathrm{HOMO}$ of the $\mathrm{S}_{0}$ state and (b) SOMO2 of the $\mathrm{T}_{1}$ state. The two drawings of each orbital correspond to views from different directions. The inset shows a schematic illustration of the frontier orbitals. 


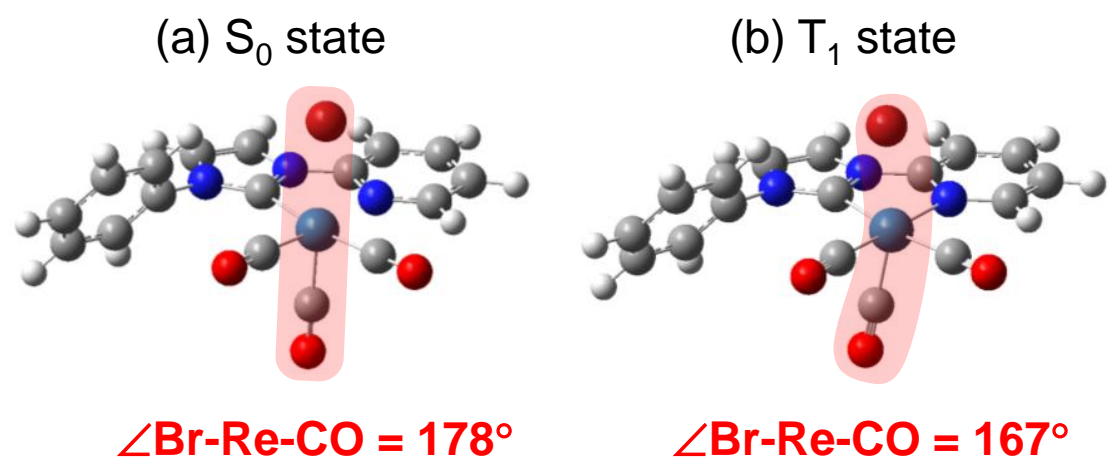

Figure 4: Optimized geometries of $\left[\operatorname{Re}(\mathrm{CO})_{3}(\mathrm{PyImPh}) \mathrm{Br}\right]$ in the (a) $\mathrm{S}_{0}$ and (b) $\mathrm{T}_{1}$ states. The red shaded area represents where the main structural changes occur between the $S_{0}$ and $T_{1}$ states.

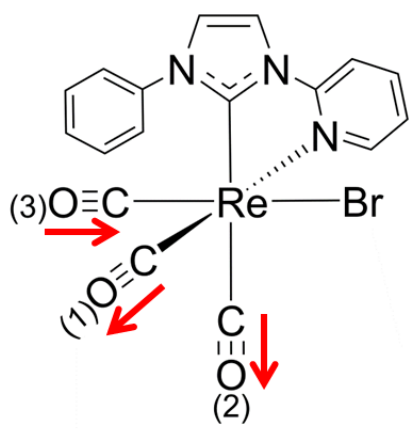

Mode 1

$\mathrm{S}_{0}: 1907 \mathrm{~cm}^{-1}$

$\mathrm{T}_{1}: 1971 \mathrm{~cm}^{-1}$

$\Delta\left(\mathrm{T}_{1}-\mathrm{S}_{0}\right)=64 \mathrm{~cm}^{-1}$

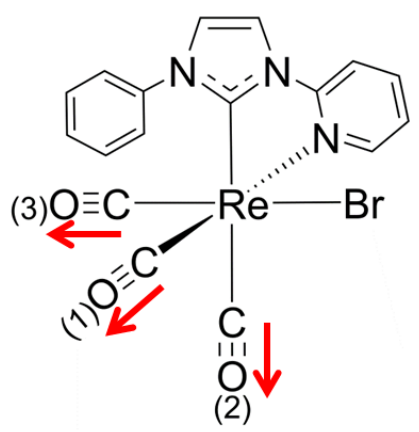

Mode 3

$\mathrm{S}_{0}: 2037 \mathrm{~cm}^{-1}$

$\mathrm{T}_{1}: 2045 \mathrm{~cm}^{-1}$

$\Delta\left(\mathrm{T}_{1}-\mathrm{S}_{0}\right)=8 \mathrm{~cm}^{-1}$

Figure 5: Vibrational phasing of the normal vibrational modes of $\left[\operatorname{Re}(\mathrm{CO})_{3}(\mathrm{PyImPh}) \mathrm{Br}\right]$ in the $\mathrm{CO}$ stretching region, their frequencies in the $\mathrm{S}_{0}$ and $\mathrm{T}_{1}$ states, and their differences. 


\subsection{TR-IR on the nanosecond timescale under non-reactive conditions}

Figure 6(a) shows the temporal evolution of the TR-IR spectra in the same wavenumber range up to $30 \mathrm{~ns}$ after photoexcitation under non-reactive conditions. The intensity of the spectra decreases with an increase in delay time but without any change in the spectral shape. The red and black circles in Figure 6(b) represent the temporal changes in the TR-IR intensities at the top of the transient absorption band at $1962 \mathrm{~cm}^{-1}$ and the bottom of the bleaching band at 1926 $\mathrm{cm}^{-1}$, respectively. Both changes display the same decay profiles and the lifetimes are approximately $23 \mathrm{~ns}$, assuming a single exponential decay (red and black lines). This lifetime is in good agreement with the reported phosphorescence lifetime ${ }^{15}$ of $22.4 \mathrm{~ns}$ at $30{ }^{\circ} \mathrm{C}$. Therefore, the observed spectral change is attributed to
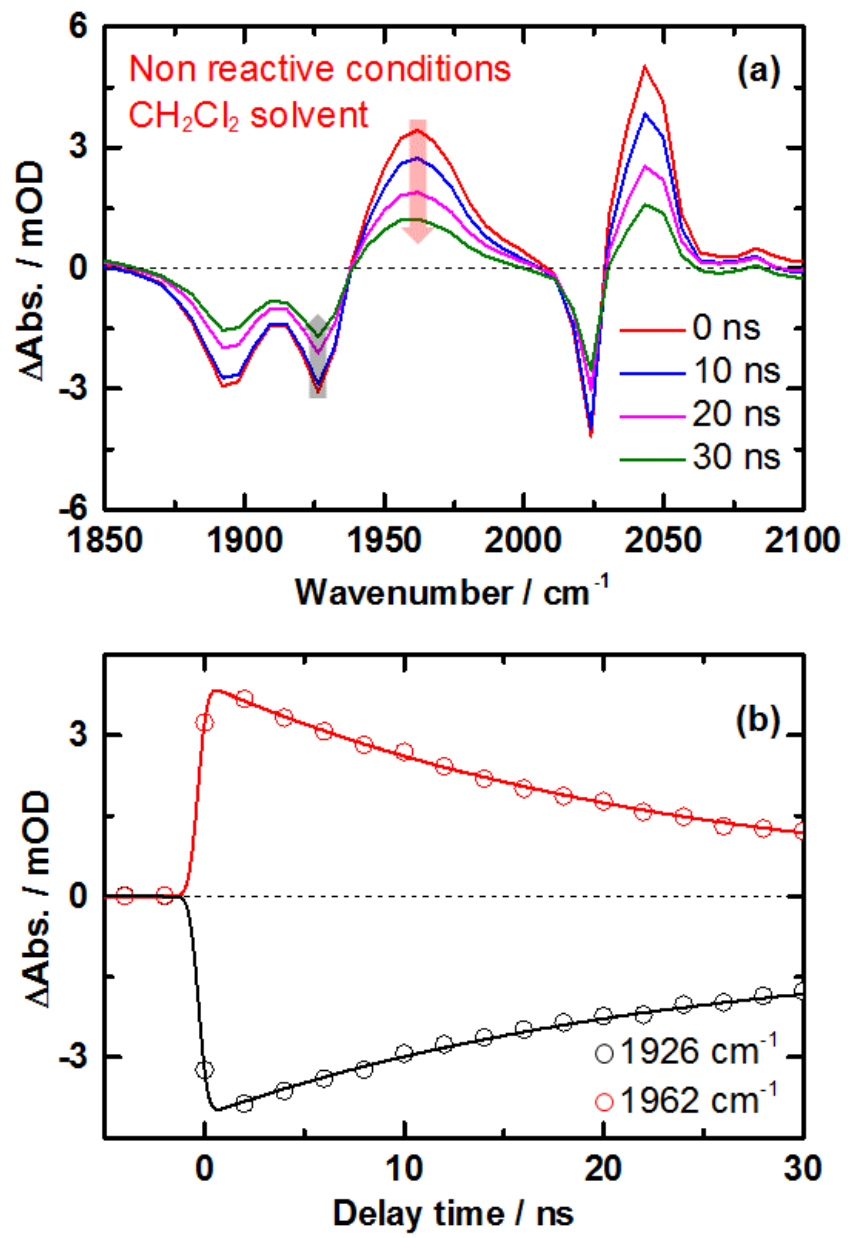

Figure 6: (a) TR-IR spectra of $\left[\mathrm{Re}(\mathrm{CO})_{3}(\mathrm{PyImPh}) \mathrm{Br}\right]$ upon excitation at $355 \mathrm{~nm}$ under non-reactive conditions. (b) Temporal profiles of $\Delta$ Abs at $1962 \mathrm{~cm}^{-1}$ (red circles) and $1926 \mathrm{~cm}^{-1}$ (black circles). The red and black lines represent the corresponding fitting curves using an exponential function convolved with a Gaussian function. relaxation from the bottom of the triplet MLCT excited state to the GS. We also observed a small component with a long lifetime of over $100 \mathrm{~ns}$, which is probably due to a thermal $\operatorname{artifact}^{29,30}$. 


\subsection{TR-IR on the nanosecond timescale under reactive conditions}

Figure 7(a) shows the temporal evolution of the TR-IR spectra over the same temporal range after photoexcitation under reactive conditions. Although the only difference is the solvent used, namely, $\mathrm{CH}_{2} \mathrm{Cl}_{2}$ for non-reactive conditions and $\mathrm{MeCN}$ for reactive conditions, the evolutions are significantly different. The intensity of the spectra decreases more quickly with an increase in delay time. However, some component remains after 30 ns, with a spectral shape obviously different from that at the beginning. To show this trend more clearly, we plotted the temporal changes in the TR-IR intensities at the bottom of the bleaching band at $1923 \mathrm{~cm}^{-1}$ (black line), at the top of the remaining band at $1941 \mathrm{~cm}^{-1}$ (red line), and at the top of the transient absorption band
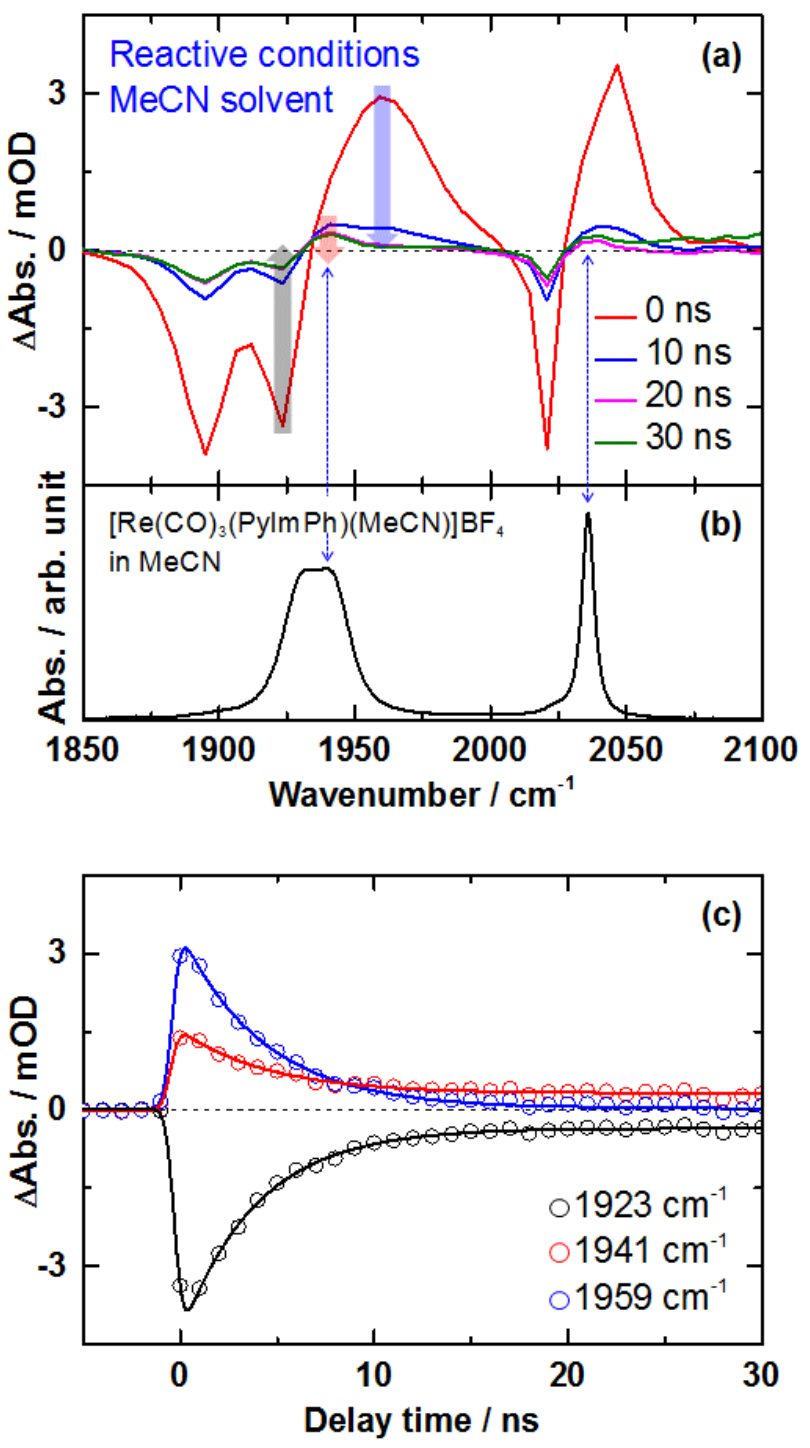

Figure 7: (a) TR-IR spectra of $\left[\operatorname{Re}(\mathrm{CO})_{3}(\mathrm{PyImPh}) \mathrm{Br}\right]$ upon excitation at $355 \mathrm{~nm}$ under reactive conditions. (b) FT-IR spectrum of a solution in $\mathrm{MeCN}$ of $\left[\mathrm{Re}(\mathrm{CO})_{3}(\mathrm{PyImPh})(\mathrm{MeCN})\right]\left[\mathrm{BF}_{4}\right]$. (c) Temporal profiles of $\Delta$ Abs at 1941 and $1959 \mathrm{~cm}^{-1}$ (red and blue circles, respectively) and $1923 \mathrm{~cm}^{-1}$ (black circles). The red, black, and blue lines represent the corresponding fitting curves usin at $1959 \mathrm{~cm}^{-1}$ (blue line) as functions of the delay time in Fig. 7(c). The temporal profile of the band at $1959 \mathrm{~cm}^{-1}$ approaches zero with a lifetime of $4.3 \mathrm{~ns}$, whereas those at 1923 and 1941 $\mathrm{cm}^{-1}$ have a component with a long lifetime of over $30 \mathrm{~ns}$, besides a component with a lifetime 
of 4.3 ns. This characteristic spectral evolution implies that a product is formed after a few nanoseconds by photoexcitation.

To determine the identity of this product, we examined the remaining transition absorption bands at 1941 and $2037 \mathrm{~cm}^{-1}$. Because these bands are located at higher wavenumbers than those of the reactant in the GS, the electron density on the Re atom is considered to be lower in the product. Among the three products shown in Figure 1, Products 1 and 3 have a lesser number of $\pi$-withdrawing CO ligands. Therefore, the electron density on the $\mathrm{Re}$ atom should be increased and the CO bands should display red shifts. In contrast, Product 2 has the same number of $\mathrm{CO}$ ligands as the reactant, but has a cationic character as a result of substitution of the $\mathrm{Br}^{-}$ligand by a neutral $\mathrm{MeCN}$ molecule. As a consequence, the electron density on the Re center should be decreased and the CO bands should display blue shifts. On the basis of this consideration, Product 2 is the most probable species to emerge after a few nanoseconds. To confirm this, we recorded the IR spectrum of a solution in $\mathrm{MeCN}$ of fac- $\left[\operatorname{Re}(\mathrm{CO})_{3}(\mathrm{PyImPh})(\mathrm{MeCN})\right]\left[\mathrm{BF}_{4}\right]$, which has the same cation as Product 2, as shown in Figure 7 (b) because Product2 has not been isolated yet. $f a c-\left[\operatorname{Re}(\mathrm{CO})_{3}(\mathrm{PyImPh})(\mathrm{MeCN})\right]\left[\mathrm{BF}_{4}\right]$ was synthesized by the thermal reaction. The structure of cationic $f a c-\left[\operatorname{Re}(\mathrm{CO})_{3}(\mathrm{PyImPh})(\mathrm{MeCN})\right]^{+}$was confirmed by the X-ray crystallographic analysis of fac- $\left[\operatorname{Re}(\mathrm{CO})_{3}(\mathrm{PyImPh})(\mathrm{MeCN})\right]\left[\mathrm{BPh}_{4}\right]$ (Figure S1 and Table S1). Because the peak positions in this spectrum are in good agreement with those of the remaining bands, we concluded that the temporal evolution of the TR-IR spectra under reactive conditions follows the production process of Product 2 in real time. 


\subsection{Temperature-dependent luminescence lifetime measurements}

Figure 8(a) shows the temperature dependence of the phosphorescence lifetime under non-reactive (red circles) and reactive (blue circles) conditions. In both cases, the lifetimes decrease as a function of temperature, so we plotted the logarithm of the rate constant $\left(\mathrm{k}_{\mathrm{obs}}\right)$ against the inverse temperature (Arrhenius plot) in Figure 8(b). The fact that both plots display a linear decrease with the same slope indicates that a non-radiative process occurs that originates from a thermally populated excited state. For a more quantitative analysis, we assumed the scheme shown in Figure 9. In this scheme, the photochemical reaction proceeds through another triplet excited state named ${ }^{3} \mathrm{X}$ under reactive conditions, and also non-radiative decay to the GS occurs through the same ${ }^{3} \mathrm{X}$ state under non-reactive conditions.

On the basis of this scheme, we formulate the following rate equations:

$$
\begin{gathered}
\frac{\mathrm{d}[\mathrm{M}]}{\mathrm{d} t}=-\left(k_{1}+k_{f}\right)[\mathrm{M}]+k_{b}[\mathrm{X}] \cdots(1) \\
\frac{\mathrm{d}[\mathrm{X}]}{\mathrm{d} t}=k_{f}[\mathrm{M}]-\left(k_{2}+k_{b}\right)[\mathrm{X}] \cdots \cdot(2)
\end{gathered}
$$

where $[\mathrm{M}]$ and $[\mathrm{X}]$ represent the concentrations of the species in the ${ }^{3} \mathrm{MLCT}$ state and the ${ }^{3} \mathrm{X}$ state, respectively, and $k_{f}$ and $k_{b}$ represent the rate constants for crossing the activation barrier in the forward and backward directions, respectively. To simplify the equation, we use $k_{1}$ to

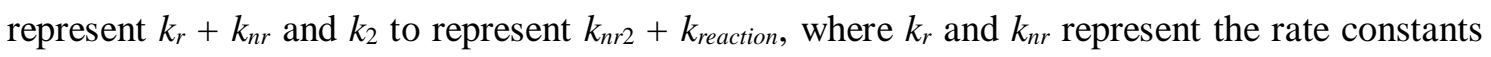
for the radiative and non-radiative processes from the ${ }^{3} \mathrm{MLCT}$ state directly to the GS, respectively, and $k_{n r 2}$ and $k_{\text {reaction }}$ represent the rate constants for non-radiative decay from the ${ }^{3} \mathrm{X}$ state to the GS and the reaction from the ${ }^{3} \mathrm{X}$ state to the product, respectively. We define $t=0$ as the time immediately after the intersystem crossing (ISC) event from the ${ }^{1} \mathrm{MLCT}$ state to the ${ }^{3}$ MLCT state.

Because the ${ }^{3} \mathrm{X}$ state is not observed in the TR-IR spectra, which is probably due to its very short lifetime, we applied the steady-state approximation to $[\mathrm{X}]$ that is $\mathrm{d}[\mathrm{X}] / \mathrm{dt}=0$. By substituting equation (1) into equation (2), we can obtain:

$$
\frac{\mathrm{d}[\mathrm{M}]}{\mathrm{d} t}=\left(-k_{1}-\frac{k_{2}}{k_{2}+k_{b}} k_{f}\right)[\mathrm{M}] \cdot \cdot(3)
$$

By defining the initial concentration in the ${ }^{3} \mathrm{MLCT}$ state at $t=0$ as $[\mathrm{M}]_{0}$, the rate equation (3) can be further solved as: 


$$
[\mathrm{M}]=[\mathrm{M}]_{0} \exp \left\{\left(-k_{1}-\frac{k_{2}}{k_{2}+k_{b}} k_{f}\right) t\right\} \cdot \cdot(4)
$$

Because the intensity of the phosphorescence is proportional to $[\mathrm{M}]$, the phosphorescence lifetime $\tau$ and its rate constant $k_{o b s}=\tau^{-1}$ are expressed by:

$$
\frac{1}{\tau}=k_{o b s}=k_{1}+\frac{k_{2}}{k_{2}+k_{b}} k_{f} \cdot \cdots(5)
$$

With respect to equation (5), we consider two cases: $k_{2}\left\langle<k_{b}\right.$ (case 1) and $\left.k_{2}\right\rangle k_{b}$ (case 2).

In case 1 , equation (5) can be rewritten as:

$$
k_{o b s}=k_{1} \cdot \cdot \cdot(6)
$$

In general, the constant $k_{1}=k_{r}+k_{n r}$ does not depend on the temperature, because it is determined by the shape of the potential energy surfaces in the ${ }^{3}$ MLCT state and the GS. Therefore, this is not the case for our observations.

In case 2 , equation (5) can be rewritten as:

$$
k_{o b s}=k_{1}+k_{f} \cdot \cdot(7)
$$

Because $k_{f}$ is the rate constant of a thermal transition, it should be a function of the temperature. Therefore, $k_{o b s}$ agrees with the experimental results and we assume that case 2 applies for further analysis. In order to obtain detailed information on the transition state, we apply the transition state theory ${ }^{31}$ to $k_{f}$ instead of the Arrhenius equation. As a result, equation (7) is expressed by:

$$
k_{o b s}=k_{1}+\frac{k_{B} T}{h} \exp \left(\frac{T \Delta S^{\ddagger}-\Delta H^{\ddagger}}{R T}\right) \cdot \cdot(8)
$$

where $\Delta S^{\ddagger}, \Delta H^{\ddagger}, R, k_{B}, h$, and $T$ are the entropy of activation, enthalpy of activation, gas constant, Boltzmann constant, Planck constant, and temperature, respectively. The absence of the constant component in Arrhenius plot indicates that the second term of equation (8) is much larger than the first term in the observed temperature region (213-313 K). In fact, fitting the data by equation (8) didn't provide any reasonable value for $\mathrm{k}_{1}$. Therefore, we assume that $k_{1}=$ 
0 and obtain the parameters $\Delta S^{\ddagger}$ and $\Delta H^{\ddagger}$ by least-squares fitting. The Gibbs free energy of activation at $298 \mathrm{~K} \Delta G_{298}^{\ddagger}$ is also estimated from $\Delta S^{\ddagger}$ and $\Delta H^{\ddagger}$.

Table 1. Estimated thermodynamic data for $\left[\operatorname{Re}(\mathrm{CO})_{3}(\mathrm{PyImPh}) \mathrm{Br}\right]$

\begin{tabular}{|c|c|c|c|}
\hline & $\Delta S^{\ddagger} / \mathrm{J} \mathrm{K}^{-1} \mathrm{~mol}^{-1}$ & $\Delta H^{\ddagger} / \mathrm{kJ} \mathrm{mol}^{-1}$ & $\Delta \mathrm{G}^{\ddagger}{ }_{298} / \mathrm{cm}^{-1}$ \\
\hline Non-reactive conditions & $-58.9 \pm 0.7$ & $11.9 \pm 0.2$ & $2460 \pm 20$ \\
\hline Reactive conditions & $-44.8 \pm 0.7$ & $11.8 \pm 0.3$ & $2100 \pm 20$ \\
\hline
\end{tabular}

Table 1 indicates the following three characteristics of the excited-state dynamics under reactive and non-reactive conditions:

(i) The values of $\Delta S^{\ddagger}$ and $\Delta H^{\ddagger}$ in non-reactive conditions are similar to those in reactive conditions.

This means that the processes in both conditions proceed through similar transition states. The small difference in $\Delta S^{\ddagger}$ indicates that there are slight differences in the structures of the transition states and the packaging of the solvents. These differences probably determine whether the reaction will proceed via non-radiative decay to the GS or to the formation of Product 2.

(ii) Both values of $\Delta S^{\ddagger}$ are negative.

This means that the transition state is more ordered than the ${ }^{3}$ MLCT state in both conditions. In a possible structure of the transition state, a solvent coordinates to or is located close to the complex. Thus, under reactive conditions, Product 2 is presumably produced by the associative mechanism. This prediction is supported by the fact that the reaction proceeds only in a solvent that has the ability to coordinate that is $\mathrm{MeCN}$.

(iii) Both values of $\Delta G^{\ddagger}$ are relatively low.

The characteristics of the ${ }^{3} \mathrm{X}$ state can be estimated from the value of $\Delta G^{\ddagger}$. In general, there are two possible assignments of the ${ }^{3} \mathrm{X}$ state: the ${ }^{3} \mathrm{MC}$ state or another ${ }^{3} \mathrm{MLCT}$ state above the lowest ${ }^{3}$ MLCT state ${ }^{32}$. The values of $\Delta G^{\ddagger}$, namely, 2460 and $2100 \mathrm{~cm}^{-1}$, are much lower than that of the reaction from the ${ }^{3} \mathrm{MLCT}$ state to the ${ }^{3} \mathrm{MC}$ state in $\left[\operatorname{Re}\left(\mathrm{X}_{2} \mathrm{bpy}\right)(\mathrm{CO})_{3}\left(\mathrm{PR}_{3}\right)\right]^{+}$, which is approximately $4000 \mathrm{~cm}^{-1}$, as reported by Koike et al. ${ }^{2}$. The magnitudes of the splitting between $\mathrm{d}$ orbitals by the ligand field in $f a c-\left[\mathrm{Re}(\mathrm{CO})_{3}(\mathrm{PyImPh}) \mathrm{Br}\right]$ and fac- $\left[\operatorname{Re}(\operatorname{diim})(\mathrm{CO})_{3}\left(\mathrm{PR}_{3}\right)\right]^{+}$should be similar because both the $\mathrm{NHC}$ and the phosphine ligands have strongly $\sigma$-donating character ${ }^{33}$. Thus, the values of $\Delta G^{\ddagger}$ for the transition from the ${ }^{3} \mathrm{MLCT}$ state to the ${ }^{3} \mathrm{MC}$ state should be similar. The large difference in $\Delta G^{\ddagger}$ between these 
complexes indicates that the transition state is not the ${ }^{3} \mathrm{MC}$ state but another type of excited state having MLCT character.

In order to confirm this assignment, we performed TD-DFT calculations using the optimized geometry of the $T_{1}$ state. The calculated energies and some other characteristics of the triplet excited states are summarized in Table 2, and the related frontier orbitals are shown in Figure 10. Because all excited states that are energetically close to the $T_{1}$ state are assigned to MLCT states, we concluded that the ${ }^{3} \mathrm{X}$ state is one of the ${ }^{3} \mathrm{MLCT}$ states and henceforth we denote the ${ }^{3} \mathrm{X}$ state as ${ }^{3} \mathrm{MLCT}(2)$.

Table 2: Calculated energies of the triplet excited states in $\left[\mathrm{Re}(\mathrm{CO})_{3}(\mathrm{PyImPh}) \mathrm{Br}\right]$

\begin{tabular}{lcccc}
\hline & Transition energy (eV) & Main components & $\%$ & Assignment \\
\hline $\mathbf{T}_{\mathbf{1}}$ & 2.35 & HOMO $\rightarrow$ LUMO & 93.7 & MLCT \\
\hline $\mathbf{T}_{\mathbf{2}}$ & 2.78 & HOMO-1 $\rightarrow$ LUMO & 95.7 & MLCT \\
\hline & & HOMO-3 $\rightarrow$ LUMO & 12.3 & \\
\cline { 2 - 3 } $\mathbf{T}_{\mathbf{3}}$ & 3.27 & HOMO-2 $\rightarrow$ LUMO & 61.7 & \multirow{2}{*}{ MLCT } \\
\cline { 2 - 3 } & & HOMO $\rightarrow$ LUMO & 3.1 & \\
\hline
\end{tabular}



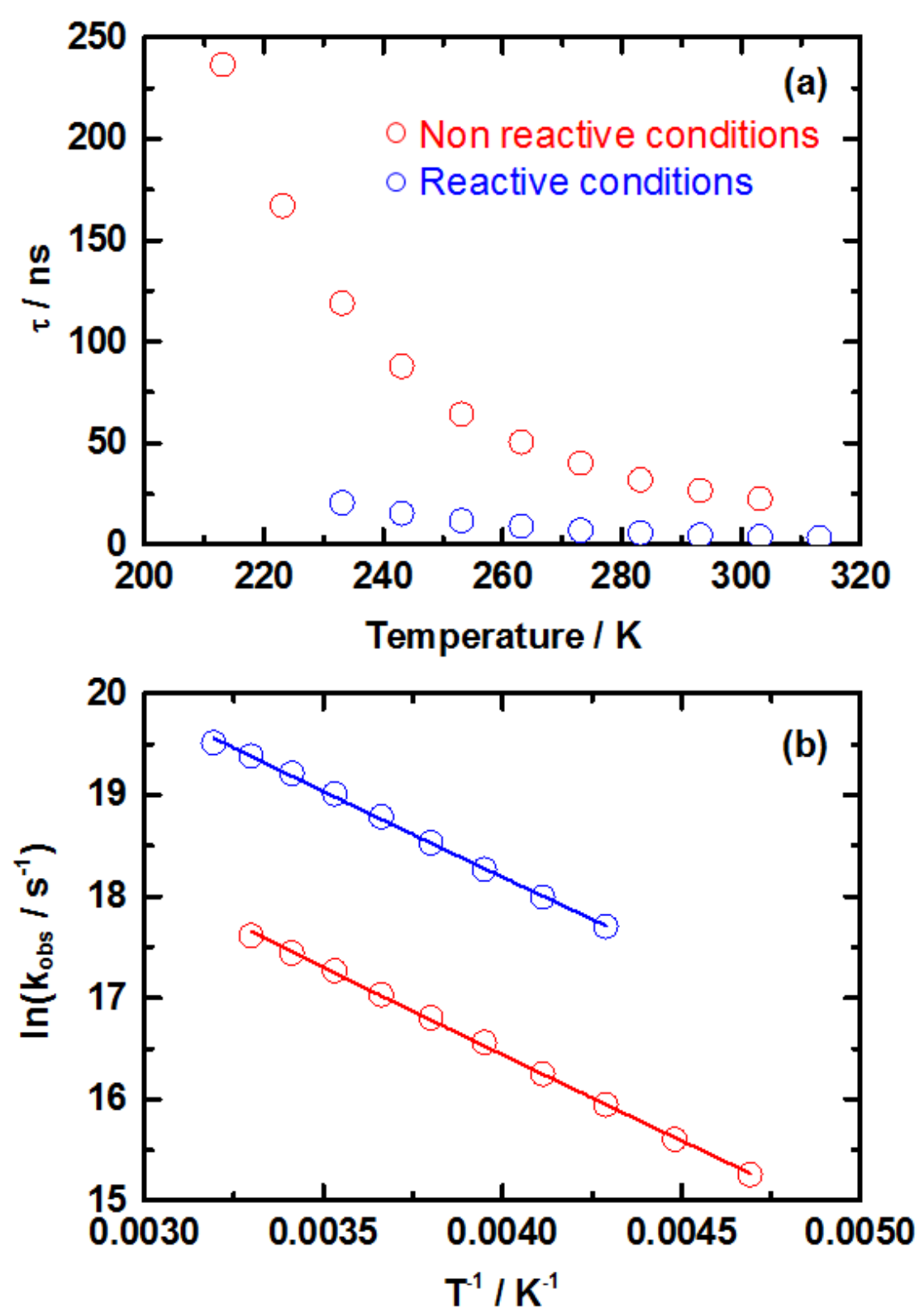

Figure 8: (a) Temperature dependence of the phosphorescence lifetime of $\left[\operatorname{Re}(\mathrm{CO})_{3}(\mathrm{PyImPh}) \mathrm{Br}\right]$ under non-reactive (red circles) and reactive (blue circles) conditions. (b) Arrhenius plots of the rate constants of the phosphorescence process (circles) and the corresponding fitting curves using equation (8) (lines) under non-reactive (red) and reactive (blue) conditions. 


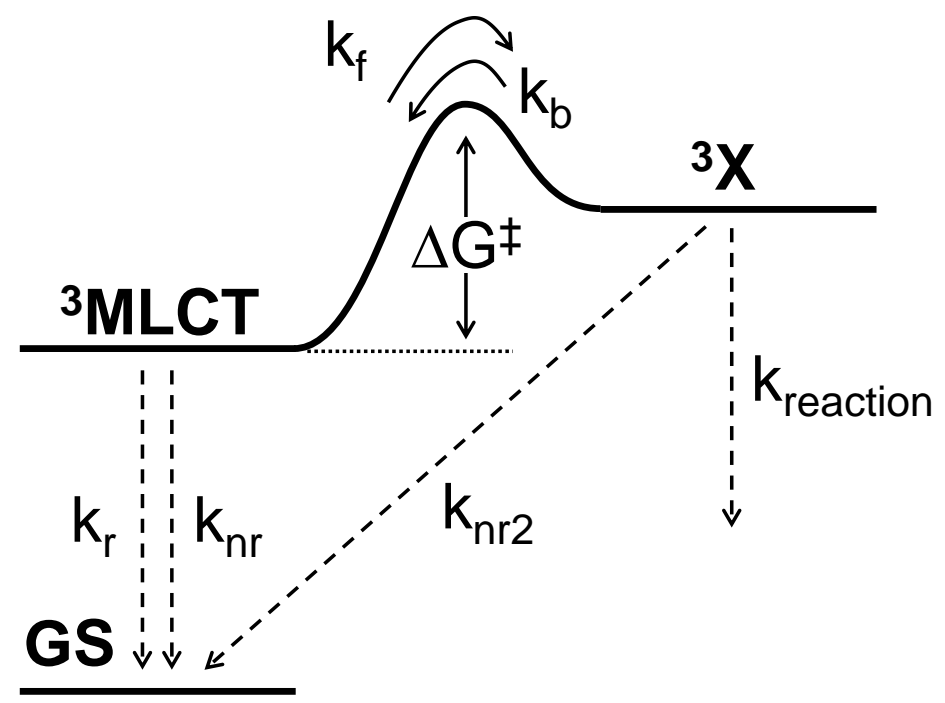

Figure 9: Scheme that we assumed for the analysis of the temperature dependence of the phosphorescence lifetime. Definitions of the symbols are given in the text. 


\section{HOMO-2}
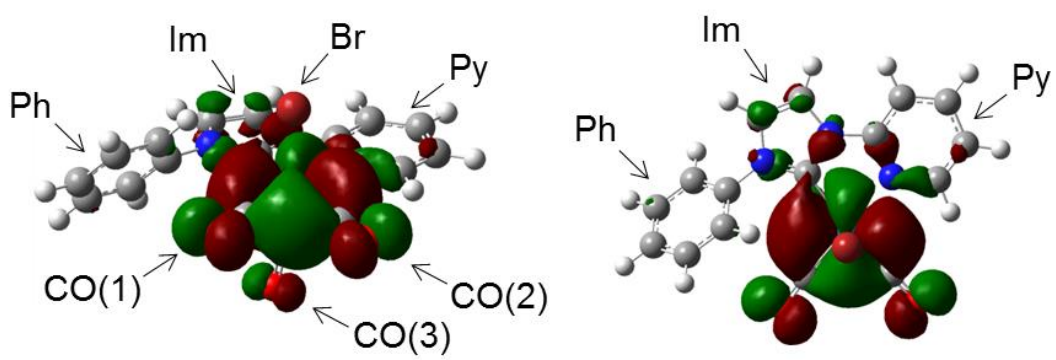

\section{HOMO-1}
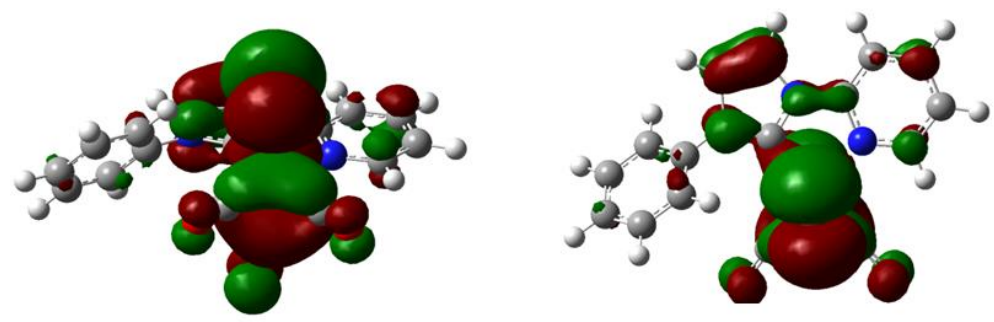

\section{HOMO}
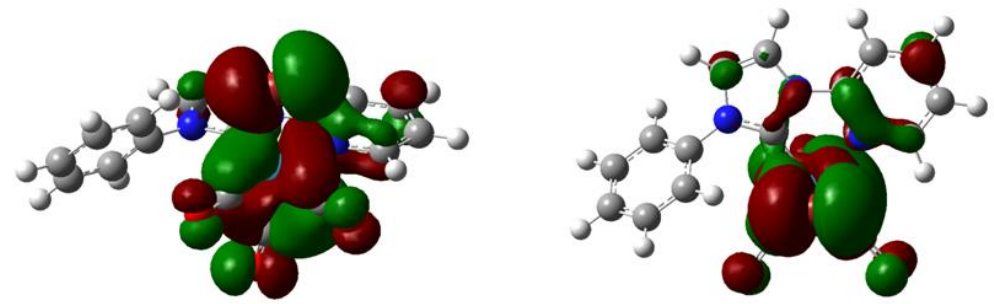

\section{LUMO}
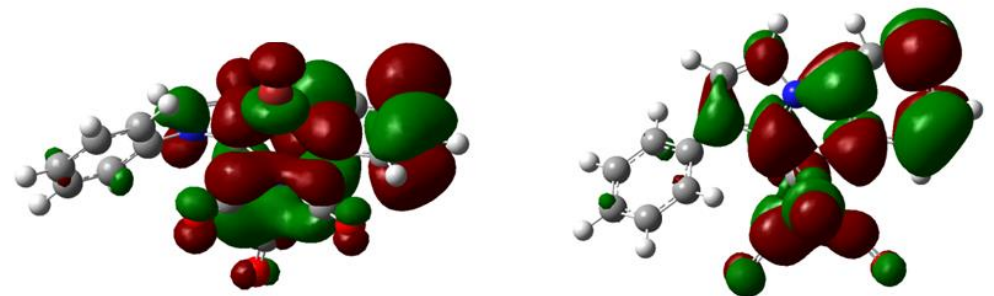

Figure 10: Molecular orbitals of $\left[\operatorname{Re}(\mathrm{CO})_{3}(\mathrm{PyImPh}) \mathrm{Br}\right]$ calculated by TD-DFT for the optimized geometry of the $T_{1}$ state. The two drawings of each orbital correspond to views from different directions. 


\subsection{Reaction pathway to Product 1 and Product 3}

Although the two other products, Products 1 and 3, are detected by experiments using continuum wave $(\mathrm{CW})$ light $^{15,16}$, they are not observed by TR-IR measurements. This is probably because Product 2 is the common intermediate and Products 1 and 3 are produced by further photoreaction of Product 2. In fact, the temporal evolution of the NMR spectra under irradiation with CW light shown in Figure 6 of the report by Vaughan et al. ${ }^{15}$ shows that there is a difference between the emergence and growth of the peaks due to Product 2 and those of Products 1 and 3. The doublet peak assigned to Product $2(8.85 \mathrm{ppm})$ emerges at $15 \mathrm{~min}$ but gradually decreases after $120 \mathrm{~min}$, whereas the doublet peaks assigned to Products 1 (8.78 ppm) and $3(8.73 \mathrm{ppm})$ emerge after $30 \mathrm{~min}$ and continuously increase until $180 \mathrm{~min}$. We confirmed this temporal evolution under irradiation with a $355 \mathrm{~nm}$ laser pulse using FT-IR spectroscopy, as shown in Figure 11(a). In the same way as the NMR spectra, the band assigned to Product 2 $\left(2036 \mathrm{~cm}^{-1}\right)$ emerges after irradiation for $15 \mathrm{~min}$, whereas those assigned to Products 1 (1833 $\left.\mathrm{cm}^{-1}\right)$ and $3\left(1865 \text { and } 1939 \mathrm{~cm}^{-1}\right)^{15}$ emerge after $60 \mathrm{~min}$. These results strongly support the suggestion that Product 2 is the common intermediate, which gives rise to Product 1 and Product 3 by further photoreactions.

We also performed the photolysis of a solution in $\mathrm{MeCN}$ of fac- $\left[\operatorname{Re}(\mathrm{CO})_{3}(\mathrm{PyImPh})(\mathrm{MeCN})\right]\left[\mathrm{BF}_{4}\right]$. It is noted that we used the $\mathrm{BF}_{4}^{-}$salt and added one equivalent of $\mathrm{Et}_{4} \mathrm{NBr}$ in order to add $\mathrm{Br}^{-}$to the solution, because it is difficult to synthesize the $\mathrm{Br}^{-}$salt by a thermal reaction. Figure 11(b) shows the corresponding FT-IR spectra before $(0$ $\mathrm{min}$ ) and after (300 min) irradiation with laser pulses at $355 \mathrm{~nm}$. After $300 \mathrm{~min}$, new peaks, which can be assigned to Product 3, emerge at 1865 and $1939 \mathrm{~cm}^{-115}$. This result indicates that Product 3, at least, is produced from $f a c-\left[\operatorname{Re}(\mathrm{CO})_{3}(\mathrm{PyImPh})(\mathrm{MeCN})\right]^{+}$by photoirradiation. However, in this measurement, we could not detect any peak assigned to Product 1 , which was probably because the $\mathrm{Br}^{-}$ion in $f a c-\left[\operatorname{Re}(\mathrm{CO})_{3}(\mathrm{PyImPh}) \mathrm{Br}\right]$ plays an important role in producing Product 1. 

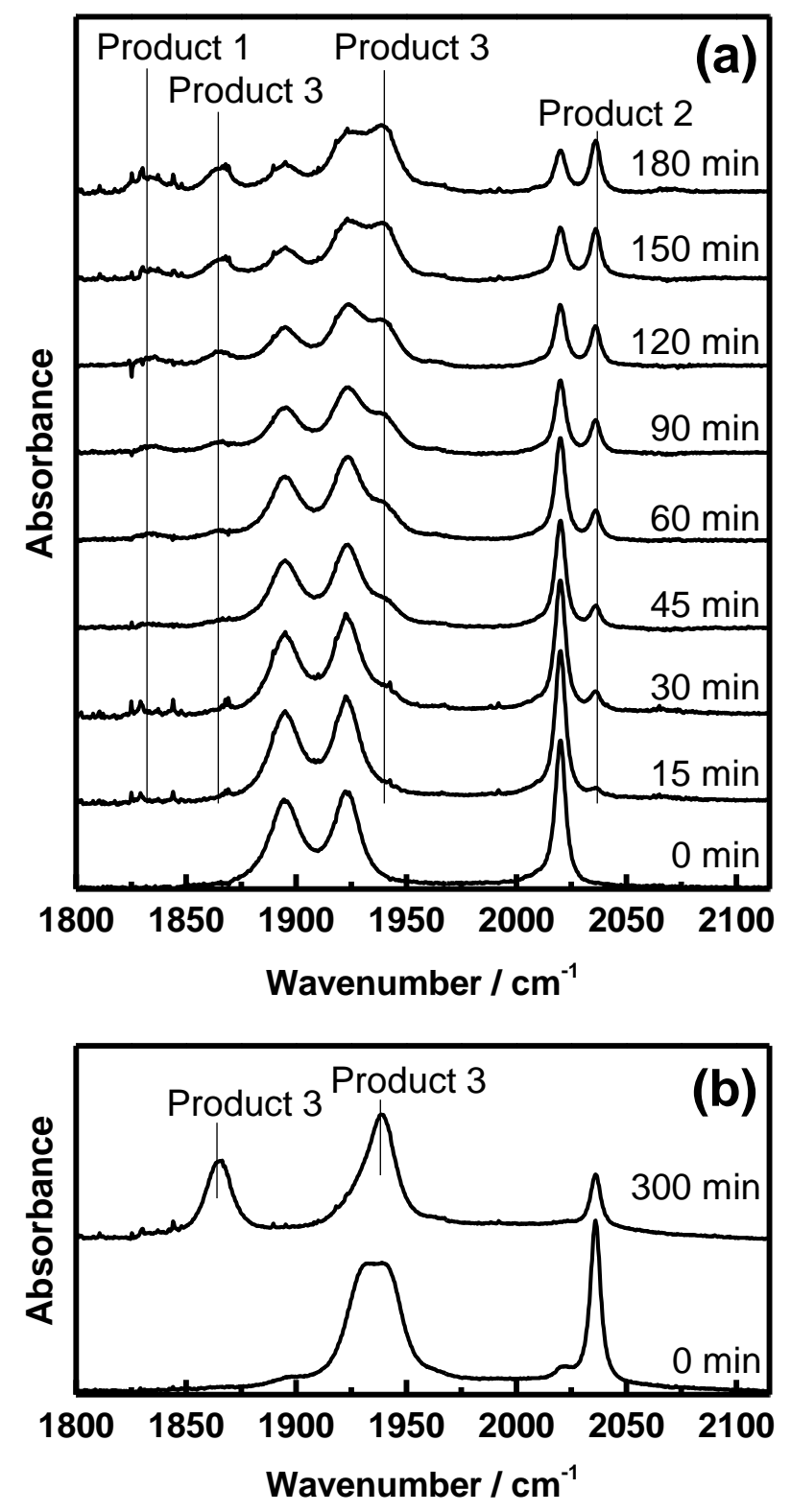

Figure 11: (a) Temporal evolution of FT-IR spectra of a solution in MeCN of $\left[\operatorname{Re}(\mathrm{CO})_{3}(\mathrm{PyImPh}) \mathrm{Br}\right]$ under laser pulse irradiation at $355 \mathrm{~nm}$. (b) FT-IR spectra of a solution in $\mathrm{MeCN}$ of $\left[\operatorname{Re}(\mathrm{CO})_{3}(\mathrm{PyImPh})(\mathrm{MeCN})\right]\left[\mathrm{BF}_{4}\right]$ and $\mathrm{Et}_{4} \mathrm{NBr}$ before $(0 \mathrm{~min})$ and after (300 min) irradiation with laser pulses at $355 \mathrm{~nm}$. 


\subsection{Revealed reaction mechanism}

Figure 12 summarizes the photochemical reaction process of $f a c-\left[\operatorname{Re}(\mathrm{CO})_{3}(\mathrm{PyImPh}) \mathrm{Br}\right]$ under reactive and non-reactive conditions. In both conditions, irradiation with light at 400 or $355 \mathrm{~nm}$ first excites the complex to the ${ }^{1}$ MLCT state, followed by rapid ISC to the ${ }^{3}$ MLCT state having ${ }^{3} \mathrm{LC}$ and ${ }^{3} \mathrm{LLCT}$ characters within 1 ps. Because the lifetime of the ${ }^{3}$ MLCT state is relatively long, the process proceeds by thermal population of the ${ }^{3} \operatorname{MLCT}(2)$ state via a transition state. The characters of the transition states are very similar in that the solvent coordinates to the complex in reactive conditions and is located close to the complex in non-reactive conditions, which indicates that the structural difference dominates the further processes. Under non-reactive conditions, non-radiative decay from the ${ }^{3} \mathrm{MLCT}(2)$ state to the GS occurs quickly, because a $\mathrm{CH}_{2} \mathrm{Cl}_{2}$ molecule cannot coordinate to the Re center. Under reactive conditions, Product 2 is produced by substitution of the $\mathrm{Br}^{-}$ligand by the solvent in addition to non-radiative decay to the GS, because a $\mathrm{MeCN}$ molecule can coordinate to the $\mathrm{Re}$ center.

The structural asymmetry in the ${ }^{3} \mathrm{MLCT}$ state probably gives rise to this unique reaction mechanism. Previously studied complexes, for example, $f a c-\left[\operatorname{Re}(\mathrm{CO})_{3}(\mathrm{bpy}) \mathrm{Cl}\right]$ and fac- $\left[\operatorname{Re}(\mathrm{CO})_{3}(\right.$ bpy $\left.) \mathrm{PR}_{3}\right]$, have $\mathrm{C}_{\mathrm{s}}$ symmetry in the GS and also have similar symmetry in the ${ }^{3} \mathrm{MLCT}$ state. In contrast, $\left[\mathrm{Re}(\mathrm{CO})_{3}(\mathrm{PyImPh}) \mathrm{Br}\right]$ undergoes a major structural change upon photoexcitation, as shown in Figure 4. This major structural change should create room for a solvent molecule to coordinate to the central $\mathrm{Re}$ atom, and the reaction proceeds by the associative mechanism. 


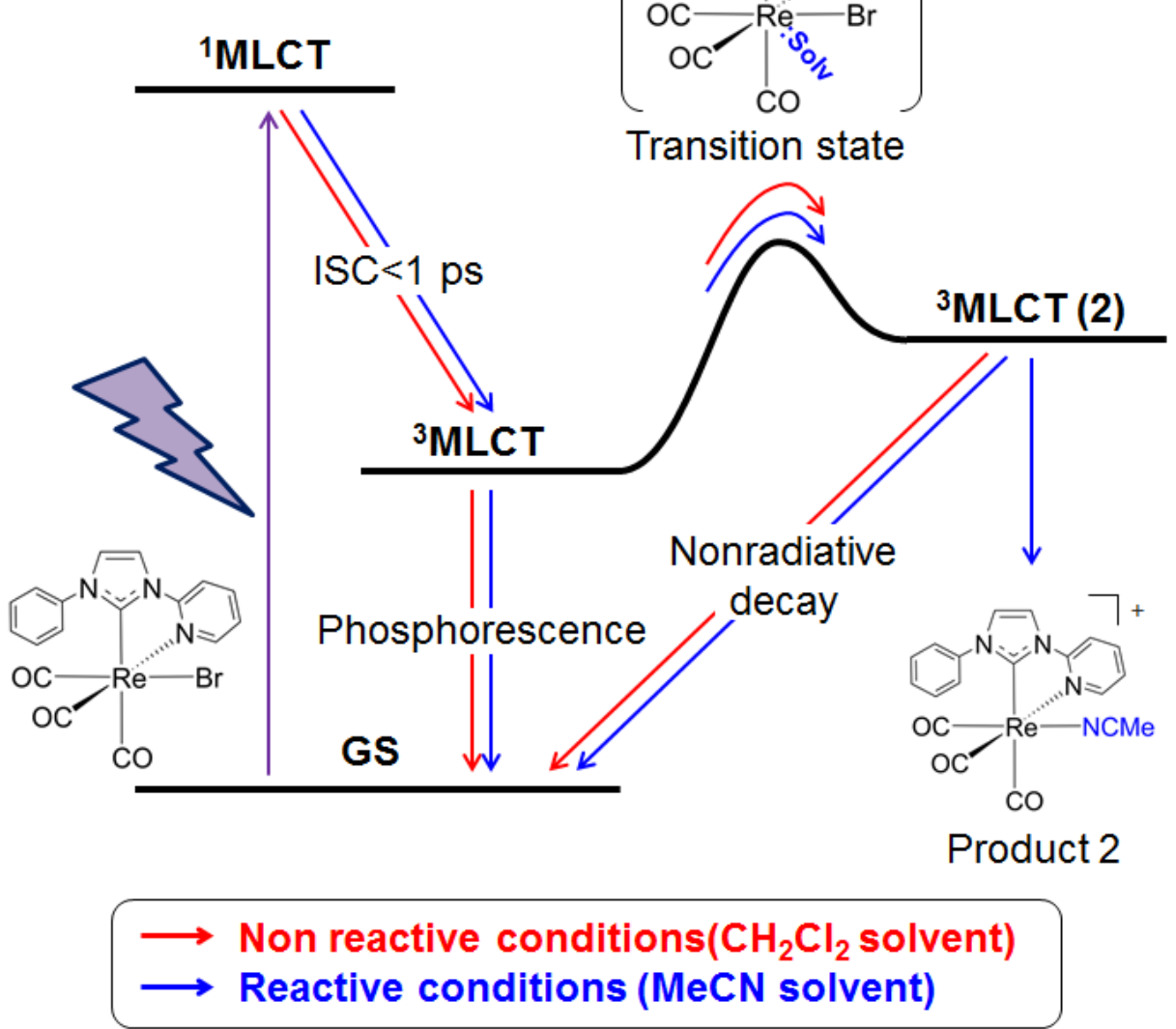

Figure 12: Proposed mechanisms of the photochemical reaction under non-reactive (red arrows) and reactive (blue arrows) conditions. 


\section{Comparison with other types of complexes}

We here compare the proposed mechanism with those of other types of $\operatorname{Re}(\mathrm{I})$ tricarbonyl complexes. As was described in the Introduction section, two types of reaction mechanism are known, namely, type I and type II. In the case of the type I mechanism in $f a c-\left[\operatorname{Re}(\mathrm{CO})_{3}(\mathrm{bpy}) \mathrm{PR}_{3}\right]^{2}$, the reaction proceeds thermally from the ${ }^{3} \mathrm{MLCT}$ state to the ${ }^{3} \mathrm{MC}$ state. The fact that the process proceeds thermally from a metastable state to a reactive state resembles the proposed mechanism; however, the following points are different. The height of the energy barrier to the reactive state $\left(\sim 4000 \mathrm{~cm}^{-1}\right)$ is much greater than that in the proposed mechanism $\left(\sim 2000 \mathrm{~cm}^{-1}\right)$ and the timescale $(\sim 1.6 \mu \mathrm{s})$ is much longer than that of the proposed mechanism $(\sim 23 \mathrm{~ns})$. These differences can be explained by the fact that the reactive intermediate state is the dissociative ${ }^{3} \mathrm{MC}$ state in the type I mechanism, whereas in the proposed mechanism it is the associative MLCT state.

In the case of the type II mechanism in a solution in $\mathrm{MeCN}$ of $f a c-\left[\operatorname{Re}(\mathrm{CO})_{3}(\mathrm{bpy}) \mathrm{Cl}\right]^{3,4}$, the reaction proceeds via highly excited states obtained by photoexcitation with high-energy light at $\sim 270 \mathrm{~nm}$. Before relaxation to the bottom of the metastable state, the process proceeds directly to two high-energy reactive states. One is a seven-coordinate state including a solvent molecule, and this reaction requires hundreds of picoseconds (associative mechanism). The other is a state having MC character and a $\mathrm{CO}$ ligand dissociates on a timescale of tens of picoseconds (dissociative mechanism). The associative mechanism is similar to the proposed mechanism, but the energy scale is largely different from that of the proposed mechanism.

\section{Conclusions}

In order to describe a new type of photoexcited ligand substitution reaction of $\operatorname{Re}(\mathrm{I})$ carbonyl complexes having an NHC ligand, we recorded TR-IR spectra on picosecond and nanosecond timescales and the temperature dependence of the luminescence lifetime of the $f a c-\left[\operatorname{Re}(\mathrm{CO})_{3}(\mathrm{PyImPh}) \mathrm{Br}\right]$ complex after photoexcitation with a pulse at 400 or $355 \mathrm{~nm}$ under reactive (in solution in $\mathrm{MeCN}$ ) and non-reactive conditions (in solution in $\mathrm{CH}_{2} \mathrm{Cl}_{2}$ ). From the analysis of these data, we concluded that the reaction proceeds thermally from a metastable triplet state to another triplet state having MLCT character via an associative transition state under both conditions. Under reactive conditions, the cationic product, namely, $f a c-\left[\operatorname{Re}(\mathrm{CO})_{3}(\mathrm{PyImPh})(\mathrm{MeCN})\right]^{+}$, is produced by substitution of the $\mathrm{Br}^{-}$ligand with a $\mathrm{MeCN}$ solvent molecule, in addition to non-radiative decay to the GS via another ${ }^{3}$ MLCT state. On the other hand, under non-reactive conditions only non-radiative decay to the GS occurs because the solvent, namely, $\mathrm{CH}_{2} \mathrm{Cl}_{2}$, cannot coordinate to the Re atom. To understand the reaction mechanisms of these complexes is important in the design of not only new Re complexes but also new catalysts for $\mathrm{CO}_{2}$ reduction and luminescent materials ${ }^{13,17-19}$. 


\section{Acknowledgements}

The authors thank Professor S. Koshihara and Dr. S. Tanaka at Tokyo Institute of Technology for variable discussions. This study was supported by the JST-PRESTO, JST-CREST, and JSPS-AnApple (All Nippon Artificial Photosynthesis Project for Living Earth). T. M. was supported by JSPS Research Fellowship for Young Scientists. Access to the facilities at the Centre for Microscopy, Characterisation and Analysis, University of Western Australia, is also kindly acknowledged. MM wishes to thank the Australian Research Council for the Future Fellowship (FT130100033).

\section{References}

(1) Sato, S.; Ishitani, O. Photochemical reactions of fac-rhenium(I) tricarbonyl complexes and their application for synthesis. Coord. Chem. Rev. 2015, 282-283, 50-59.

(2) Koike, K.; Okoshi, N.; Hori, H.; Takeuchi, K.; Ishitani, O.; Tsubaki, H.; Clark, I. P.; George, M. W.; Johnson, F. P. A.; Turner, J. J. Mechanism of the Photochemical Ligand Substitution Reactions of fac-[Re(bpy) $\left.(\mathrm{CO})_{3}\left(\mathrm{PR}_{3}\right)\right]^{+}$Complexes and the Properties of Their Triplet Ligand-Field Excited States. J. Am. Chem. Soc. 2002, 124, 11448-11455.

(3) Sato, S.; Morimoto, T.; Ishitani, O. Photochemical Synthesis of mer-[Re(bpy) $\left.(\mathrm{CO})_{3} \mathrm{Cl}\right]$. Inorg. Chem. 2007, 46, 9051-9053.

(4) Sato, S.; Sekine, A.; Ohashi, Y.; Ishitani, O.; Blanco-Rodríguez, A. M.; Vlček, A.; Unno, T.; Koike, K. Photochemical Ligand Substitution Reactions of fac-[Re(bpy) $\left.(\mathrm{CO})_{3} \mathrm{Cl}\right]$ and Derivatives. Inorg. Chem. 2007, 46, 3531-3540.

(5) Sato, S.; Matubara, Y.; Koike, K.; Falkenström, M.; Katayama, T.; Ishibashi, Y.; Miyasaka, H.; Taniguchi, S.; Chosrowjan, H.; Mataga, N.; Fukazawa, N.; Koshihara, S.; Onda, K.; Ishitani, O. Photochemistry of fac-[Re(bpy) $\left.(\mathrm{CO})_{3} \mathrm{Cl}\right]$. Chem. - Eur. J. 2012, 18, 15722-15734.

(6) Ko, C.-C.; Lo, L. T.-L.; Ng, C.-O.; Yiu, S.-M. Photochemical Synthesis of Intensely Luminescent Isocyano Rhenium(I) Complexes with Readily Tunable Structural Features. Chem. - Eur. J. 2010, 16, 13773-13782.

(7) Tso-Lun Lo, L.; Lai, S.-W.; Yiu, S.-M.; Ko, C.-C. A new class of highly solvatochromic dicyano rhenate(I) diimine complexes - synthesis, photophysics and photocatalysis. Chem. Commun. 2013, 49, 2311-2313.

(8) Yamamoto, Y.; Sawa, S.; Funada, Y.; Morimoto, T.; Falkenström, M.; Miyasaka, H.; Shishido, S.; Ozeki, T.; Koike, K.; Ishitani, O. Systematic Synthesis, Isolation, and Photophysical Properties of Linear-Shaped Re(I) Oligomers and Polymers with 2-20 Units. $J$. Am. Chem. Soc. 2008, 130, 14659-14674.

(9) Yamamoto, Y.; Tamaki, Y.; Yui, T.; Koike, K.; Ishitani, O. New Light-Harvesting Molecular 
Systems Constructed with a Ru(II) Complex and a Linear-Shaped Re(I) Oligomer. J. Am. Chem. Soc. 2010, 132, 11743-11752.

(10) Morimoto, T.; Nishiura, C.; Tanaka, M.; Rohacova, J.; Nakagawa, Y.; Funada, Y.; Koike, K.; Yamamoto, Y.; Shishido, S.; Kojima, T.; Saeki, T.; Ozeki, T.; Ishitani, O. Ring-Shaped Re(I) Multinuclear Complexes with Unique Photofunctional Properties. J. Am. Chem. Soc. 2013, 135, 13266-13269.

(11) Takeda, H.; Koike, K.; Inoue, H.; Ishitani, O. Development of an Efficient Photocatalytic System for $\mathrm{CO}_{2}$ Reduction Using Rhenium(I) Complexes Based on Mechanistic Studies. J. Am. Chem. Soc. 2008, 130, 2023-2031.

(12) Cheung, A. W.-Y.; Lo, L. T.-L.; Ko, C.-C.; Yiu, S.-M. Synthesis, Functionalization, Characterization, and Photophysical Study of Carbonyl-Containing Isocyano Rhenium(I) Diimine Complexes. Inorg. Chem. 2011, 50, 4798-4810.

(13) Li, X.-W.; Li, H.-Y.; Wang, G.-F.; Chen, F.; Li, Y.-Z.; Chen, X.-T.; Zheng, Y.-X.; Xue, Z.-L. Blue-Green Luminescent Rhenium(I) Tricarbonyl Complexes with Pyridine-Functionalized N-Heterocyclic Carbene Ligands. Organometallics 2012, 31, 3829-3835.

(14) Casson, L. A.; Muzzioli, S.; Raiteri, P.; Skelton, B. W.; Stagni, S.; Massi, M.; Brown, D. H. $\mathrm{N}$-Heterocyclic carbenes as $\pi^{*}$-acceptors in luminescent $\operatorname{Re}(\mathrm{I})$ triscarbonyl complexes. Dalton. Trans 2011, 40, 11960-11967.

(15) Vaughan, J. G.; Reid, B. L.; Ramchandani, S.; Wright, P. J.; Muzzioli, S.; Skelton, B. W.; Raiteri, P.; Brown, D. H.; Stagni, S.; Massi, M. The photochemistry of rhenium(I) tricarbonyl N-heterocyclic carbene complexes. Dalton. Trans 2013, 42, 14100-14114.

(16) Vaughan, J. G.; Reid, B. L.; Wright, P. J.; Ramchandani, S.; Skelton, B. W.; Raiteri, P.; Muzzioli, S.; Brown, D. H.; Stagni, S.; Massi, M. Photophysical and Photochemical Trends in Tricarbonyl Rhenium(I) N-Heterocyclic Carbene Complexes. Inorg. Chem. 2014, 53, 3629-3641.

(17) Huckaba, A. J.; Sharpe, E. A.; Delcamp, J. H. Photocatalytic Reduction of $\mathrm{CO}_{2}$ with Re-Pyridyl-NHCs. Inorg. Chem. 2016, 55, 682-690.

(18) Liyanage, N. P.; Dulaney, H. A.; Huckaba, A. J.; Jurss, J. W.; Delcamp, J. H. Electrocatalytic Reduction of $\mathrm{CO}_{2}$ to $\mathrm{CO}$ With Re-Pyridyl-NHCs: Proton Source Influence on Rates and Product Selectivities. Inorg. Chem. 2016, 55, 6085-6094.

(19) Stanton, C. J.; Machan, C. W.; Vandezande, J. E.; Jin, T.; Majetich, G. F.; Schaefer, H. F.; Kubiak, C. P.; Li, G.; Agarwal, J. Re(I) NHC Complexes for Electrocatalytic Conversion of $\mathrm{CO}_{2}$. Inorg. Chem. 2016, 55, 3136-3144.

(20) Liard, D. J.; Busby, M.; Matousek, P.; Towrie, M.; Vlček, A. Picosecond Relaxation of ${ }^{3}$ MLCT Excited States of $\left[\operatorname{Re}(\text { Etpy })(\mathrm{CO})_{3}(\mathrm{dmb})\right]^{+}$and $\left[\operatorname{Re}(\mathrm{Cl})(\mathrm{CO})_{3}(\mathrm{bpy})\right]$ as Revealed by Time-Resolved Resonance Raman, UV-vis, and IR Absorption Spectroscopy. J. Phys. Chem. A 
2004, 108, 2363-2369.

(21) Li, G.; Parimal, K.; Vyas, S.; Hadad, C. M.; Flood, A. H.; Glusac, K. D. Pinpointing the Extent of Electronic Delocalization in the Re(I)-to-Tetrazine Charge-Separated Excited State Using Time-Resolved Infrared Spectroscopy. J. Am. Chem. Soc. 2009, 131, 11656-11657.

(22) Mukuta, T.; Fukazawa, N.; Murata, K.; Inagaki, A.; Akita, M.; Tanaka, S.; Koshihara, S.; Onda, K. Infrared Vibrational Spectroscopy of $\left[\mathrm{Ru}(\mathrm{bpy})_{2}(\mathrm{bpm})\right]^{2+}$ and $\left[\mathrm{Ru}(\mathrm{bpy})_{3}\right]^{2+}$ in the Excited Triplet State. Inorg. Chem. 2014, 53, 2481-2490.

(23) Tanaka, S.; Takahashi, K.; Hirahara, M.; Yagi, M.; Onda, K. Characterization of the excited states of distal- and proximal-[Ru(tpy)(pynp) $\left.\mathrm{OH}_{2}\right]^{2+}$ in aqueous solution using time-resolved infrared spectroscopy. J. Photochem. Photobiol., A 2015, 313, 87-98.

(24) Tanaka, S.; Matsubara, Y.; Asatani, T.; Morimoto, T.; Ishitani, O.; Onda, K. Structural deformation of a ring-shaped $\operatorname{Re}(\mathrm{I})$ diimine dinuclear complex in the excited state. Chem. Phys. Lett. 2016, 662, 120-126.

(25) Mukuta, T.; Tanaka, S.; Inagaki, A.; Koshihara, S.; Onda, K. Direct Observation of the Triplet Metal-Centered State in $\left[\mathrm{Ru}(\mathrm{bpy})_{3}\right]^{2+}$ Using Time-Resolved Infrared Spectroscopy. ChemistrySelect 2016, 1, 2802-2807.

(26) Frisch, M. J.; Frisch, M. J.; Trucks, G. W.; Schlegel, H. B.; Scuseria, G. E.; Robb, M. A.; Cheeseman, J. R.; Scalmani, G.; Barone, V.; Mennucci, B.; Petersson, G. A.; Nakatsuji, H.; Caricato, M.; Li, X.; Hratchian, H. P.; Izmaylov, A. F.; Bloino, J.; Zheng, G.; Sonnenberg, J. L.; Hada, M.; Ehara, M.; Toyota, K.; Fukuda, R.; Hasegawa, J.; Ishida, M.; Nakajima, T.; Honda, Y.; Kitao, O.; Nakai, H.; Vreven, T.; Montgomery, J. A., Jr.; Peralta, J. E.; Ogliaro, F.; Bearpark, M.; Heyd, J. J.; Brothers, E.; Kudin, K. N.; Staroverov, V. N.; Kobayashi, R.; Normand, J.; Raghavachari, K.; Rendell, A.; Burant, J. C.; Iyengar, S. S.; Tomasi, J.; Cossi, M.; Rega, N.; Millam, J. M.; Klene, M.; Knox, J. E.; Cross, J. B.; Bakken, V.; Adamo, C.; Jaramillo, J.; Gomperts, R.; Stratmann, R. E.; Yazyev, O.; Austin, A. J.; Cammi, R.; Pomelli, C.; Ochterski, J. W.; Martin, R. L.; Morokuma, K.; Zakrzewski, V. G.; Voth, G. A.; Salvador, P.; Dannenberg, J. J.; Dapprich, S.; Daniels, A. D.; Farkas, Ö.; Foresman, J. B.; Ortiz, J. V.; Cioslowski, J.; Fox, D. J. Gaussian09, Revision B.01; Gaussian, Inc., Wallingford, CT, 2009.

(27) Butler, J. M.; George, M. W.; Schoonover, J. R.; Dattelbaum, D. M.; Meyer, T. J. Application of transient infrared and near infrared spectroscopy to transition metal complex excited states and intermediates. Coord. Chem. Rev. 2007, 251, 492-514.

(28) Dattelbaum, D. M.; Omberg, K. M.; Schoonover, J. R.; Martin, R. L.; Meyer, T. J. Application of Time-Resolved Infrared Spectroscopy to Electronic Structure in Metal-to-Ligand Charge-Transfer Excited States. Inorg. Chem. 2002, 41, 6071-6079.

(29) Bromberg, S. E.; Yang, H.; Asplund, M. C.; Lian, T.; McNamara, B. K.; Kotz, K. T.; Yeston, J. S.; Wilkens, M.; Frei, H.; Bergman, R. G.; Harris, C. B. The Mechanism of a C-H Bond 
Activation Reaction in Room-Temperature Alkane Solution. Science 1997, 278, 260-263.

(30) Yuzawa, T.; Kato, C.; George, M. W.; Hamaguchi, H.-O. Nanosecond Time-Resolved Infrared Spectroscopy with a Dispersive Scanning Spectrometer. Appl. Spectrosc. 1994, 48, 684-690.

(31) Glasstone, S.; Laidler, K. J.; Eyring, H. The Theory of Rate Processes. McGraw-Hill: New York, 1941.

(32) O’Donnell, R. M.; Johansson, P. G.; Abrahamsson, M.; Meyer, G. J. Excited-State Relaxation of Ruthenium Polypyridyl Compounds Relevant to Dye-Sensitized Solar Cells. Inorg. Chem. 2013, 52, 6839-6848.

(33) Hudson, Z. M.; Sun, C.; Helander, M. G.; Chang, Y.-L.; Lu, Z.-H.; Wang, S. Highly Efficient Blue Phosphorescence from Triarylboron-Functionalized Platinum(II) Complexes of N-Heterocyclic Carbenes. J. Am. Chem. Soc. 2012, 134, 13930-13933. 